\title{
Zwischen Makulatur und Modernisierung: Zur Viabilität reflexiver Institutionen
}

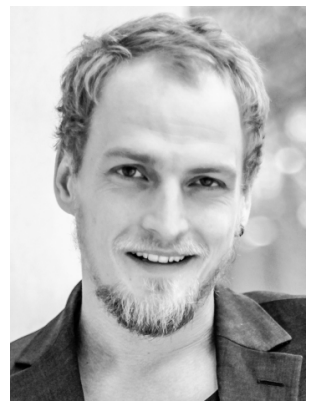

über die nun auch die Form der Institutionalisierung reflexiver Managementinstrumente operationalisiert werden kann. Die Ergebnisse der Fallstudie (in der Tradition sozioökonomischer Begleitforschung) zeigten, dass nicht allein die Ausprägung des reflexiven Moments organisationaler Modernisierungsbemühungen, sondern auch der Sinnbezug - ihre Institutionalisierung - Einfluss auf deren Wirksamkeit haben. Gemessen wurde dabei jedoch nicht Performanz im üblich quantitativen Sinne unternehmenstheoretischer Studien, sondern Viabilität in von Glasersfelds Lesart.

This paper examines the question to which extent reflexive institutions adequately serve their actual purpose - perpetual modernization. Therefore all (more or less formalized, regularized) practices to promote innovation were outlined as an arrangement of organizational learning. In a case study, these practices were conceptualized as potentially reflexive institutions and analyzed by the theory of institutional reflexivity. From a conceptual point of view, this article proposes criteria to operationalize the way and shape reflexive management tools are institutionalized because the case study results (in the tradition of accompanying socioeconomic research) showed that not only the degree of the reflexive moment, but also the nature of its institutionalization influences the efficacy of striving for modernization. Performance has not been understood and assessed in the conventional quantitative sense of organization studies, however, as viability in von Glasersfeld's sense of the word.

Institutionelle Reflexivität, Organisationales Lernen, Evolutorischer Institutionalismus, Unternehmenstheorie, Sozioökonomik, Fallstudie

Institutional Reflexivity, Organizational Learning, Evolutionary Institutionalism, Theory of the Firm, Socio-Economics, Case Study

\section{Einleitung}

Unternehmen operieren in Spannungsfeldern sich widersprechender Erfordernisse: Sie brauchen Regeln, damit ihr Handeln stabil und berechenbar wird, müssen aber auch flexibel bleiben, also diese Regeln variieren und modifizieren können. Sie müssen sich auf et- 
was spezialisieren, was andere nicht können, und müssen zugleich Neues erproben, ohne sich zu verzetteln. Doch wie schaffen es Firmen, diese kontradiktorischen Anforderungen zu verarbeiten und vor allem: Was hindert sie daran? Der vorliegende Artikel nimmt sich dieser Problemstellung an.

\subsection{Modernisierung mittels (nicht trotz) Institutionen}

Betriebliche Modernisierungsbemühungen sind im Wirtschaftssystem, wie es sich in den westlichen Ländern etablierte, längst keine singulären Angelegenheiten mehr. Unternehmensberater und Managementforscher entwickeln eifrig Vorgehensmodelle und formulieren Handlungsempfehlungen, die Organisationen beim Kampf gegen die fortwährende Tendenz zur Verfestigung helfen sollen. Bestritten wird diese Tendenz jedenfalls nicht: Weder aus Sicht des methodologischen Individualismus, dessen Vertreter u.a. „kognitiver Leichtigkeit" das Primat einräumen (vgl. Kahneman 2012), noch aus Sicht des methodologischen Institutionalismus, nach dem vor allem „sozial sanktionierbare Erwartungen“ (Dietl 1993, 37), eingespielte Handlungsmuster und normative Leitbilder, Individuen von der „Bürde der Entscheidung“ entlasten (Berger/Luckmann 2004, 57). Der Fundus an modernisierungsverheißenden Managementtools wuchs dabei in den letzten Dekaden beträchtlich an. Nicht selten avancieren sie zu „Managementmoden“ (vgl. Kieser 1997), derer sich kaum noch entzogen werden kann - denn, dass Organisationen sogar Reformen institutionalisieren und damit permanenten Wandel suggerieren, nur um den Anforderungen ihrer Umwelt zu entsprechen, wissen wir spätestens seit Brunsson/Olsen (1993). Warum aber bleiben die Effekte dieser über Jahrzehnte erprobten und laufend verfeinerten Managementinstrumente immer noch so oft hinter ihren Erwartungen zurück? Schätzungsweise scheitern etwa 70\% aller Change-Projekte (vgl. Moldaschl 2009, 301).

In diesem Beitrag wird davon ausgegangen, dass sich die beobachtbaren Performanceunterschiede zwischen Unternehmen nicht aus der bloßen Existenz und Anzahl initiierter Modernisierungsprogramme (organisationaler Lernaktivitäten) erklären, sondern vielmehr aus der Form ihrer Anwendung. Im Fokus dieses Artikels stehen deshalb Institutionen, hier konzipiert als Verfahren, Einrichtungen, Regeln, die ihren Gegenstand (und bestenfalls auch noch sich selbst) systematisiert hinterfragen, formalisierte Skepsis sozusagen. Es wird untersucht, ob der Einsatz dieser (zunächst nur potenziell) reflexiven Institutionen einer Modernisierung auch zuwiderlaufen kann und wenn ja, ob sich die Genese dieses unzulänglichen (kontraintuitiven) Gebrauchs reflexiver Verfahren rekonstruieren bzw. erklären lässt. Im Fokus steht dabei vor allem die (dialektische) Beziehung zwischen Reflexivität und ihrer Institutionalisierung. Ob tiefgreifende Reformen oder alltägliche Lernprozesse: Selbst die Anwendung standardisiertester Managementinstrumente unterliegt einer unternehmensspezifischen Formatierung, die maßgeblich für deren Wirksamkeit ist. Was diesen „,spirit“ of organizational action“ (Moldaschl et al. 2012, 3) ausmacht, sind nicht die Menschen, durch die eine Organisation vorübergehend verkörpert wird, sondern gerade das, was die Organisationsmitglieder überdauert: „Members come and go, and leadership changes, but organizations' memories preserve certain behaviors, mental maps, norms, and values over time“ (Hedberg 1981, 6).

Nachfolgend werden das konzeptionelle Fundament und die forschungsleitende Fragestellung des Artikels entwickelt, wie auch das forschungsmethodische Vorgehen einer adäquaten empirischen Untersuchung zu ihrer Beantwortung definiert. Mit einer explorativen Fallstudie wird daraufhin nicht nur deutlich gemacht, wie vielschichtig und kontingent 
sich organisationale Lernprozesse in praxi darstellen. Es konnte außerdem ein Operationalisierungsschema der Institutionalisierung organisationaler Lernprozesse - komplementär zu jenem der Reflexivität - abgeleitet werden, womit nun auch Einsichten zur Wechselwirkung von Reflexivität und Institutionalisierung gewonnen werden können. Der Beitrag schließt mit einer konkludierenden Diskussion der Ergebnisse und den Limitationen der Untersuchung.

\subsection{Organisationales Lernen als dialektische Konzeption}

Die Organisations- und Managementforschung hat es sich zur Aufgabe gemacht, Phänomene des Lernens in bzw. von Organisationen zu erklären. Vor dem Hintergrund der beobachtbaren Performanceunterschiede zwischen Unternehmen können es einige offensichtlich besser als andere. Das nunmehr mannigfaltige Repertoire organisationaler Lerntheorien sieht sich dabei wiederkehrender Kritik ausgesetzt, u.a. am inhärenten Zirkelschluss ihrer Argumentation oder der inhaltlichen Entleerung begrifflicher Konstrukte (vgl. Moldaschl 2006, 3 f.; Schirmer/Knödler/Tasto 2012, 21 ff.). Dabei ist der Grund für die weitschweifige, heterogene Theorielandschaft nicht zuletzt ihr widersprüchlicher Unterbau. Auf diese konzeptionelle Kontradiktion verwies bereits Weick/Westley (1999, 190): „Organizing and learning are essentially antithetical processes, which means the phrase ,organizational learning' qualifies as an oxymoron“. Die beiden Kernattribute organisationalen Lernens divergieren damit ihrer gängigen Bedeutungszuschreibung nach. Wird Lernen, das mit Veränderung, Flexibilität, Dynamik oder Reflexion assoziiert ist, auf organisationaler Ebene gedacht, also überindividuell, entpersonifiziert und nicht zufallsabhängig, so impliziert das auch Stabilität, Orientierung, Routine oder Institutionalisierung. Damit beschreiben beide Bestandteile entgegengesetzte Pole ein und desselben Kontinuums. Ein Dilemma, denn ein und dieselbe Sache lässt sich nicht gleichzeitig in entgegengesetzte Richtungen denken. „Ein und derselbe Prozess könne nicht gleichzeitig stabilisierend und destabilisierend wirken“ (Schirmer 2013, 7).

Doch kann die Existenz von Institutionen organisationales Lernen nicht ausschließlich hemmen. Denn dann unterläge die Argumentation einem Kurzschluss, sind doch Institutionen zugleich auch die Ergebnisse organisationalen Lernens. Und umgekehrt: Wenn Institutionen die Ergebnisse organisationalen Lernens sind (womit sich ferner die Beständigkeit organisationaler Handlungssysteme nicht unwesentlich begründet), kann auch organisationales Lernen nicht frei von Regelhaftigkeit stattfinden, werden doch Institutionen erst durch ihre ordnungsbildende Form überhaupt erkenn- und analysierbar. Die kontraintuitiven Folgen dieses Verhältnisses bringen Argyris/Schön (2006, 285) auf den Punkt: „Die Handlungen, die wir vornehmen, um das produktive Lernen in Organisationen zu fördern, verhindern in Wirklichkeit ein tiefergehendes Lernen“. Das zwingt nun Management- und Organisationsforscher dazu, Wege zu finden, jene Dialektik in ihren theoretischen Ansätzen zu verarbeiten. Moldaschl (2006) konzipiert den kontradiktorischen Kern organisationalen Lernens als institutionalisierte Reflexivität bzw. reflexive Institutionen: Wenn sich Stabilität und Gewissheit institutionalisieren lassen, warum dann nicht auch Veränderung und Reflexion bzw. „Reflexivität“ als Eigenschaft sozialer Systeme, Verfahrensweisen und Strukturen. Moldaschl (2006) formt aus diesem Widerspruch die scheinbar widersinnige Idee, man könne Ermöglichungsbedingungen kreativen Handelns in Regeln gießen. Es ist ein epistemologischer Ansatz, der zugleich nach theoretischen Erklärungen seiner eigenen Negation sucht. Aus konzeptioneller Sicht wird das bewusste und kontinuierliche Infrage- 
stellen des Wissens und der Sichtweisen in Organisationen als reflexive Institutionen modelliert, womit sämtliche (mehr oder weniger formalisierte) Managementtools in Unternehmen einer Analyse unterzogen werden können - vorausgesetzt sie sind institutionalisiert und verfügen über ein reflexives Moment, bezwecken also Modernisierung auf überindividueller Ebene (womit es sich auch von individuellem Lernen unterscheidet). Reflexivität, als Eigenschaft von Institutionen, unterliegt dabei einer differenzierteren Konnotation als es im alltäglichen Sprachgebrauch üblich ist. Sie umfasst neben dem bewussten Aufgreifen der eigenen Handlungsbedingungen (Selbstbezüglichkeit), „unerwünschte Folgen zielgerichteten Handelns“ (Nebenfolgen), „die Herkunft und Situiertheit des eigenen Wissens“ (Wissensabhängigkeit), wie auch die „Grenzen seiner Gültigkeit" (vgl. Moldaschl 2005b, 362 ff.). Um betriebliche Arrangements damit als Instrument organisationalen Lernens zu modellieren, sollten sie (vor allem in Abgrenzung zu alternativen organisationstheoretischen Begriffsbestimmungen von Reflexivität) wenigstens zwei dieser drei Merkmalsausprägungen aufweisen.

„Unter Reflexivitätsverdacht“ stehen in dieser Konzeption zunächst einmal sämtliche organisationale Regeln, Verfahren, Einrichtungen oder Praktiken (eben Institutionen), die der „Beobachtung, Überprüfung, Evaluierung und Entwicklung vorhandener Regelsysteme dienen“" (Moldaschl 2013, 131). Das verlangt schon ihr originärer Zweck - Routinenmodernisierung mittels Modernisierungsroutinen. Die Identifikation solcher potenziell reflexiven Institutionen orientiert sich dabei an den folgenden Indikatoren, die Moldaschl (vgl. 2011, 41) zur Analyse des Vorhandenseins von Reflexivität in Institutionen vorschlägt:

(A) „Selbstbeobachtung und Selbstkritik“, womit Regeln und Verfahrensweisen fortwährend infrage gestellt und kontinuierliche Verbesserung provoziert werden, bspw. in Form von Organisationseinheiten (Inhouse Consulting, Organisationsentwicklung, Performance Management), aber auch tool- bzw. projektförmig, mit prominenten Beispielen wie der „Balanced Scorecard“ (vgl. Kaplan/Norton 1992), „Lean Management“ (vgl. Womack/Jones 2003) oder „TRIZ“ (vgl. Altschuller 1986).

(B) „Rückgriff auf Fremdbeobachtung“, bezieht sich im Ansatz auf das mittlerweile viel beforschte „Absorptive Capacity“-Konzept (vgl. Cohen/Levinthal 1990), das sich dediziert mit der Aufnahme externen Wissens als unternehmerische Fähigkeit beschäftigt; wobei sich Wissen in der hier angewandten Analytik auf selbstbezügliches beschränkt, also auf Metawissen, z.B. in Form von Kritik durch Berater, Beiräte, Audits oder mittlerweile auch über die Anzahl „digitaler Likes“.

(C) „Kommunikativer Bezug auf Fremdreferenz“ als verständiger (teils rechenschaftsverpflichteter) Rückbezug auf Fremdwahrnehmung, bspw. etabliert in Form von Berichtspraktiken zu „Corporate Social Responsibility“ (CSR-Report) oder zu „Environment, Health and Safety" (EHS-Report), aber auch firmenintern, mit Fortschrittsüberwachungsprozessen von Projekten wie dem "Stage-gate System“ (vgl. Cooper 1990).

(D) „Offene Evaluierung von Handlungsfolgen“, um unerwartete bzw. unerwünschte Nebenfolgen zu identifizieren, bspw. durch den Einsatz von „Employee Engagement Surveys“ oder „Customer Surveys“ oder auch „Lessons Learned“.

(E) „Entwurf alternativer Gegenwarten und Zukünfte“, als das gezielte Aufgreifen der Kontingenz möglicher Entwicklungsverläufe, hypothetisches Denken in alternativen Pfaden und Szenarien sowie Kreativitätspraktiken à la „Design Thinking“ (vgl. Kelley/Littman 2002) oder dem Planungswerkzeug „4DX“ (vgl. Covey/McChesney/ Huling 2016). 
Die Spanne solcher betrieblichen Praktiken reicht dabei von standardisierten Methoden und Tools bis hin zu firmen- und branchenspezifischen Restrukturierungsinitiativen und temporären Veränderungsprogrammen. Wenn sich nun organisationale Arrangements in den genannten Dimensionen verorten lassen (Reflexivität kann dabei auch in mehr als einer der zuvor genannten Dimensionen angelegt sein), ist das zwar ein Indikator für das Vorhandensein von Reflexivität, gibt aber noch keine Auskunft über deren qualitative Ausprägung. Erst anhand der Kriterien in Tabelle 1 lässt sich der Grad, also das Ausmaß der installierten Reflexivität erfragen bzw. bewerten.

\begin{tabular}{|c|c|c|}
\hline Kriterium & Operationalisierung & Datentyp \\
\hline $\begin{array}{l}\text { Zahl der Kanäle für } \\
\text { Rückkopplungen und } \\
\text { Grad der Kopplung }\end{array}$ & $\begin{array}{l}\text { Wie viele externe Referenzen (z.B. Berater, Wissenschaft- } \\
\text { ler, Kritiker) bzw. Verfahren (z.B. Benchmarking, Ran- } \\
\text { king) werden wie regelmäßig genutzt? }\end{array}$ & $\begin{array}{l}\text { Quantita- } \\
\text { tiv }\end{array}$ \\
\hline $\begin{array}{l}\text { Reichweite des Einbe- } \\
\text { zugs von Fernwirkun- } \\
\text { gen }\end{array}$ & $\begin{array}{l}\text { Welche Akteure und Systeme werden hinsichtlich welcher } \\
\text { Folgen in welchem räumlichen und zeitlichen Horizont in } \\
\text { das Monitoring einbezogen? }\end{array}$ & $\begin{array}{l}\text { Quantita- } \\
\text { tiv \& qua- } \\
\text { litativ }\end{array}$ \\
\hline $\begin{array}{l}\text { Möglichkeit der Krite- } \\
\text { rien- und Zielrevision }\end{array}$ & $\begin{array}{l}\text { Inwieweit sind diese in den Selbstbewertungen prinzipiell } \\
\text { vorgesehen und zulässig? Welche Maßstäbe und Ziele ste- } \\
\text { hen zur Prüfung, welche werden tabuisiert? }\end{array}$ & Qualitativ \\
\hline $\begin{array}{l}\text { Grad der Anwendung } \\
\text { bzw. Aussetzung refle- } \\
\text { xiver Verfahren }\end{array}$ & $\begin{array}{l}\text { Hat die Anwendung eines Verfahrens überhaupt Konse- } \\
\text { quenzen? Falls ja, welchen Stellenwert hat es im Entschei- } \\
\text { dungsprozess? Werden Bereiche und Fälle der Aussetzung } \\
\text { begründet/diskutiert? }\end{array}$ & $\begin{array}{l}\text { Quantita- } \\
\text { tiv \& qua- } \\
\text { litativ }\end{array}$ \\
\hline Selbstanwendung & $\begin{array}{l}\text { Inwieweit wird das jeweilige Prüfverfahren selbst zum Ge- } \\
\text { genstand der Prüfung? In welchem Umfang werden ge- } \\
\text { scheiterte Maßnahmen verarbeitet oder verdrängt? }\end{array}$ & Qualitativ \\
\hline
\end{tabular}

Tabelle 1: Kriterien zur Bewertung der Reflexivität institutionalisierter Arrangements (Moldaschl 2011, 42)

Nun stehen zwar solche Einrichtungen unter Generalverdacht, Routiniertes infrage zu stellen. Ihr Zweck verlangt es schließlich so. Doch selbst wenn sich das Vorhandensein reflexiver Institutionen indizieren lässt, ihre qualitative Ausgestaltung für angemessen befunden wurde, ist mittlerweile vielfältig nachgezeichnet, dass sich der eigentliche Zweck häufig vom tatsächlichen Ergebnis unterscheidet, unter vielen beispielsweise mit Fallstudien zu „Kaizen“ und „Produktentstehungsprozessen“ (vgl. Hallensleben/Wörlen/Moldaschl 2015), „der Etablierung eines integrierten Gesundheitsmanagements“ (vgl. Hallensleben 2015) oder auch zu „quergestellten Netzwerkgruppen“ (vgl. Jain/Hallensleben/Manger 2013). Als Erklärung für diese Abweichungen konnten systemtheoretische (vgl. Luhmann 1969), (mikro)politische (vgl. Schirmer 2016), diskurs- (vgl. Hallensleben/Jain 2016), wie auch differenz- und kontingenztheoretische (vgl. Jain/Manger 2016) Ursachen herausgearbeitet werden (zusammenfassend siehe Moldaschl 2009, 304). Neben diesen etablierten Erklärungsansätzen wird in diesem Artikel auf eine Art inhärente Dysfunktionalität abgestellt, indem der Zusammenhang verschiedenartiger Ausprägungen von Reflexivität und ihrer Institutionalisierung in den Fokus gerückt wird. 


\section{Institutionen als unscharfer, aber konzeptioneller Kern organisationaler Lerntheorien}

Neben der Theorie Institutioneller Reflexivität bauen Ansätze zu organisationalem Lernen nicht selten argumentativ (teils implizit, teils explizit) auf Institution(alisierung)en (Argyris/Schön 1974; Farjoun 2010; Feldman/Pentland 2003; Schreyögg/Kliesch-Eberl 2007). Ihren konzeptionellen Fokus richten sie aber auf die Art und Weise des Lernens, also die Reflexions- bzw. Lernprozesse, häufig unterteilt in Ebenen und differenziert nach Intensität oder Auslöser. Dabei erhält das ohnehin schon weitläufige und schwammige Konstrukt der Institutionalisierung in keinem der theoretischen Ansätze eine konkrete Analytik und entzieht sich damit der Möglichkeit einer präzisen Operationalisierung.

Auch in den bislang durchgeführten Studien zu institutionalisierter Reflexivität wurde primär die Ausgestaltung der Reflexivität (also die Dimension des Lernens) anhand oben aufgeführter Kriterien einer systematischen Analyse unterzogen (vgl. Hallensleben 2016; Jain/Hallensleben/Manger 2013; Manger 2016; Moldaschl et al. 2012; Schirmer/Knödler/ Tasto 2012). Doch wenn es Institutionen sind, an welchen theoretische Modelle organisationales Lernen rekonstruieren, dann ist auch eine Analytik zu ihrer Untersuchung nötig. Ein wesentliches Ziel hinter der forschungsleitenden Motivation dieses Beitrags ist es daher, Kriterien zur Analyse der Institutionalisierungsform organisationaler Lernprozesse zu entwickeln. Es wird argumentiert, dass die Wirksamkeit organisationaler Lernaktivitäten nicht nur vom Ausmaß der Reflexivität abhängt, sondern auch maßgeblich vom Sinn, in dessen Horizont sie institutionalisiert werden, und, dass beide Elemente (Reflexivität und ihre Institutionalisierung) einander bedingen. Reflexivität und ihre Institutionalisierung bergen demnach die Gefahr inadäquater Ausgestaltung und können Ursache dafür sein, dass organisationale Arrangements „das Papier nicht wert sind, auf das sie geschrieben wurden“, um auf den Titel des Beitrags zu rekurrieren. Deshalb schlägt dieser Artikel eine Modifikation bei der Bewertung der Sinndimension vor - hier eben ausgeführt mit der Theorie Institutioneller Reflexivität.

Wie lassen sich nun aber Eigenschaften von etwas herausarbeiten, das weder physisch greifbar ist, noch gedanklich scharfe Konturen besitzt, etwas, das also erst aus der reinen empirischen Beobachtung in Erscheinung treten kann? Eine Möglichkeit ist, auf bestehende theoretische Ansätze zurückzugreifen, so etwa auf Scotts Institutionenmodell. Scott (vgl. 2001, 51 ff.) differenziert darin drei Arten von Institutionen anhand der Mechanismen ihrer Legitimitätsbildung bzw. Durchsetzung (,regulativ, normativ und kulturell-kognitiv"). Scott unterscheidet mit dem Modell grundlegende Ausprägungen gesellschaftlicher Stabilitätsprozesse. Weil jedoch reflexive Institutionen den Untersuchungsgegenstand dieses Beitrags bilden, d.h. vor allem bewusst geschaffene Modernisierungsroutinen in Unternehmensorganisationen, rücken weitere gestaltbeschreibende Eigenschaften in den Vordergrund, weshalb Scotts Ansatz den Gegenstand nicht vollumfänglich beschreiben würde und sich deshalb unter dem Aspekt der „Legitimität“ subsumiert. Auch Parsons/Turner (vgl. 1991, 37 f.) strukturfunktionalistische Unterscheidung zwischen „relationalen, regulativen, kulturellen Institutionen“, die sich im Kern an der Vermittlung von Individuum und Gemeinschaft ausrichtet, lieferte keine vollumfängliche Klassifikation zur Unterscheidung der Merkmale konkreter institutioneller Ausgestaltung von Lernaktivitäten in Unternehmen. Sowohl Scott (2001) als auch Parsons/Turner (1991) bieten zwar jeweils eine Typologisierung, die verschiedene Arten von Institutionen voneinander unterscheidet, nicht jedoch formbeschreibende Attribute als mehrdimensionale Ausprägungen einzelner Institutionen desselben Typs. Die zweite (hier angewandte) Möglichkeit ist, eher pragmati(zis- 
ti)sch vorzugehen, d.h. aus der analytisch-empirischen Identifikation institutionalisierter Praktiken Fragen zu formulieren und diese schließlich auf institutionentheoretischer Basis zu kategorisieren. Denn auch die wissenschaftliche Analyse ist ein „theory-laden undertaking “: „Observation of $\mathrm{x}$ is shaped by prior knowledge of $\mathrm{x}$ “ (Hanson 1958, 19). Dieser Ansatz verarbeitet damit bewusst die Theoriebeladenheit wissenschaftlicher Beobachtung. Zunächst ist also das konzeptionelle Verständnis von Institutionen zu schärfen (in welcher Gestalt, mit welchen Funktionen und Mechanismen treten sie zutage; wie werden sie definiert, abgegrenzt und analysiert), denn was sichtbar wird, hängt mit Popper (1977) davon ab, worauf „der Scheinwerfer“ gerichtet ist. Erst mit dieser theoretischen Basis entsteht ein Bezugspunkt für die empirische Beobachtung in der Fallstudie, können Auffälligkeiten und Kausalbeziehungen identifiziert und letztlich auch das Wechselwirken zwischen Institutionalisierung und Reflexivität analysiert werden. Die Entwicklung der Operationalisierung in Frageform, wie auch deren Kategorisierung folgen dabei einem zirkulären Prozess.

Um nun die handlungsregulierende Gestalt institutioneller Arrangements gesamtheitlich beschreiben zu können und dabei zu berücksichtigen, dass das Institutionenverständnis auf eine facettenreiche Tradition zurückblicken lässt - der Begriff nicht nur breitbandig angelegt ist, sondern auch disziplinübergreifend Anwendung findet - werden Institutionen hier verstanden als „vom Handeln abgelöste, mehr oder weniger stabilisierte Ordnungssysteme“ (Moldaschl 2007b, 37). Ihre Entstehung (Institutionalisierung) vollzieht sich entweder emergent, also in einem „Prozess, in dem sich der Grad der Kopplung sozialer Systeme und Aktivitäten verstärkt“ oder intensional, d.h. mittels einer „gezielten Schaffung von Institutionen, welche Entscheidungen beobachten und evaluieren, professionalisieren und kritisieren“" (Moldaschl 2006, 17). Auf dieser weitgefassten Basis soll das Begriffskonstrukt der Institution(alisierung) nun mittels nachfolgend detailliert beschriebener Operationalisierungskriterien weiter geschärft werden. Neben soziologischer wurde dazu auch ökonomische Literatur rezipiert. Die herausdestillierten Attribute zur Beschreibung der Gestalt und Spezifität institutioneller Arrangements lassen sich schließlich unter folgenden fünf Chiffren subsumieren.

\section{Legitimität}

Die Macht von Institutionen „beruht auf der Akzeptierung durch Individuen oder auf dem Zwang, den Individuen auf andere Individuen ausüben“ (Hollis 1995, 149). Ohne Legitimität, deren „Abwesenheit Prozesse der Infragestellung provoziert“ (Koch/Schemmann 2009, 126), verlieren Institutionen ihre Stabilität und handlungsregulierende Wirkung. Und umgekehrt: Legitimation erhält bzw. setzt den Prozess der Institutionalisierung in Gang (vgl. Deephouse/Suchman 2008, 58). Damit „bedarf die institutionale Welt der Legitimation, das heißt, sie braucht Weisen ihrer ,Erklärung' und Rechtfertigung “ (Berger/ Luckmann 2004, 66), vor allem wenn Erfolg ausbleibt (vgl. Deephouse/Suchman 2008, 63). Spannungen können auch dann entstehen, wenn Organisationen mit inkompatiblen Vorschriften aus verschiedenen institutionellen Logiken konfrontiert werden (vgl. Greenwood et al. 2011, 318).

\section{Formalität}

Institutionen als „soziologischer Tatbestand“ („faits sociaux“), im weitesten Sinne „jede mehr oder minder festgelegte Art des Handelns“ (Durkheim 1965, 114), „transformieren 
kulturelle Wertorientierungen in eine normativ verbindliche soziale Ordnung “ (Eder 1997, 159). Sie bezeichnen „ein System (...) formgebundener (formaler) und formungebundener (informeller) Regeln (Normen) einschließlich der Vorkehrungen zu deren Durchsetzung“ (Richter/Furubotn 2003, 7). Die Institutionalisierung von Praktiken, als eine Form der Normalisierung, vermittelt tendenziell das Gefühl von Sicherheit (vgl. Moldaschl 2005a, 279): „Institutions are social structures that have attained a high degree of resilience (...), [they] provide stability and meaning to social life" (Scott 2001, 48). Doch bedeutet mehr Formalität nicht per se mehr Stabilität im Ordnungssystem.

\section{Faktizität (Instanziierung)}

„Institutionalisierung ist ein Verfahren der Praxis, mit dem sich Systeme und Individuen von der Notwendigkeit permanenter Aufmerksamkeitszuwendung, Prüfung und Verhandlung entlasten, um ihre Vermögen anderweitig zu investieren, und auch um Fehlerraten zu senken“ (Moldaschl 2005b, 368). Dadurch entstehen institutionelle Instanzen, die zur Erfüllung konkreter Zwecke dienen. Sie sind vom Urheber mehr oder weniger entkoppelt. Denn Institutionen „werden als über und jenseits der Personen, welche sie ,zufällig“ im Augenblick verkörpern, daseiend erlebt" (Berger/Luckmann 2004, 62) - d.h. entpersonifiziert. „Sie entlasten das einzelne Organisationsmitglied davon, die Vorgehens- und Koordinationsweisen stets neu erfinden oder überprüfen zu müssen." (Moldaschl 2007b, 37). Faktizität umfasst neben dem Grad ihrer Objektivation auch ihre Beständigkeit (dem Alter) und gibt damit Auskunft über ihre Widerstandsfähigkeit. Denn „sind sie erst einmal entstanden, [zeigen Institutionen] eine Neigung zur Dauerhaftigkeit" (Berger/Luckmann 2004, 86). „Institutions by definition are the more enduring features of social life“ (Giddens 1984, 24).

\section{Signifikanz}

Institutionen strukturieren nicht nur Aufmerksamkeit (vgl. Thornton/Ocasio 2008, 113 f.), sie selbst können Gegenstand von Aufmerksamkeit sein. Das setzt voraus, dass sie als solche erkannt, also „gehört, aufgezeichnet, klassifiziert und mit einer Reihe von Akteuren und strategischen Handlungen assoziiert werden können" (vgl. eng. Thornton/Ocasio 2008, 122). Für gewöhnlich erfüllen intensional geschaffene (reflexive) Institutionen diesen Tatbestand. „Sie sind für alle Mitglieder der jeweiligen (...) Gruppe erreichbar" (Berger/Luckmann 2004, 58). Damit kann ihre Bedeutung vor dem Hintergrund möglicher Alternativen beispielsweise anhand der Mittelzuwendung, der Unterstützung und Bewerbung durch das Top-Management und schließlich an ihrem Einfluss auf das Handeln beurteilt werden. Institutionen sind die „rules of the game“ (North 1990, 3) und damit Begrenzung („humanly devised constraints“; North 1991, 97) und Ermöglichung („generative Grammatiken“; Moldaschl 2007b, 37) zugleich.

\section{Durchsetzungsmechanismen}

Institutionen sind in anderen Worten „sozial sanktionierbare Erwartungen“ (Dietl 1993, 37), zwischen formellen Regeln und informellen Zwängen (vgl. North 1991, 97), ein kontingentes Set aus Regeln, Prämien und Sanktionen (vgl. Jackall 2010, 118). „Ein wesentlicher Aspekt der Wirkungsweise von Institutionen ist daher die Kostspieligkeit der Feststellung von Übertretungen und die Schwere der Strafe" (North 1992, 4). Vermittelt über ihre 
Sanktionierbarkeit und/oder Belohnung leisten Institutionen „soziale Integration“ (vgl. Schelsky 1970, 15).

Diese, aus einschlägiger Literatur exzerpierten, konstruktspezifischen Kriterien weisen Interdependenzen auf, wie den obigen Ausführungen zu entnehmen ist, gehen jedoch nicht ineinander auf. Abstrahiert und aggregiert werden die genannten Operationalisierungskriterien in folgender tabellarischer Übersicht noch einmal zusammenfassend in griffige Gestalt gebracht. Diese Kriterien sind weder unumstößlich noch scharf voneinander abgrenzbar. Sie dienen lediglich der anschaulicheren Bündelung der Operationalisierungsaspekte in Frageform.

\section{Kriterium \\ (und eine synoptische \\ Begriffsbestimmung)}

Legitimität

Grad der Infragestellung reflexiver Institutionen.

\section{Formalität}

Intensität der Reglementierung und Verfahrensförmigkeit reflexiver Institutionen.

\section{Faktizität (Instanziierung)} Grad der Objektivität (Entpersonifizierung, Beständigkeit) reflexiver Institutionen.

\section{Signifikanz}

Bedeutung und Priorität unter Alternativen, Höhe der Mittelzuwendung und Grad der Bekanntheit.

Durchsetzungsmechanismen Ausmaß reglementierter und angewandter (einschließlich informeller) Mechanismen zur Durchsetzung - sowohl Sanktionierung als auch Belohnung.

\section{Operationalisierungsvorschlag}

Wird die Notwendigkeit, Gültigkeit bzw. Sinnhaftigkeit infrage gestellt (von der Direktion, Mitarbeitern, Gruppen, Organisationseinheiten)? Erfordert die Anwendung disziplinarische Maßnahmen oder erfolgt sie freiwillig? Führt die strukturelle Einbettung zu Interessenkonflikten und Mikropolitik?

Ist die reflexive Institution aufbau- (strukturell, z.B. im Organigramm, in Tätigkeitsbeschreibungen) und ablauforganisatorisch (z.B. in der Prozesslandkarte) integriert (formale Institutionalisierung)? Wird sie in offiziellen Dokumenten reglementiert oder basiert sie auf implizitem Wissen (informelle Institutionalisierung)? Sind sich die Akteure ihrer Existenz überhaupt bewusst?

Wie lange existiert sie bereits? Wie resistent ist sie gegenüber Veränderungsabsichten (,institutional layering, conversion oder drift")? Wurde bereits versucht, sie durch Alternativen zu substituieren (,institutional displacement“)? Ist der Fortbestand an einen bzw. eine Gruppe von Mitarbeitern gebunden (Entkopplung vom Urheber)? Wird der Erfolg/ Misserfolg einzelnen Akteuren zugeschrieben?

Wie viel Bedeutung misst ihr das Unternehmen unter den Modernisierungsbemühungen bei (z.B. Budgetierung, Allokation von Ressourcen, Berichtsstruktur oder strategische Relevanz)? Wie hoch ist der Bekanntheitsgrad in der Belegschaft? Werden relevante Mitarbeiter bzw. Organisationseinheiten auch funktionsund bereichsübergreifend involviert?

Wie verbindlich ist ihre Einhaltung? Wird Nichteinhaltung sanktioniert (z.B. Machtentzug) und Befolgung belohnt (z.B. „harte“ Zielvereinbarungen oder „weiche“ Incentivierungsmechanismen)? Werden Ausnahmen zugelassen? Wie viele Freiheitsgrade werden gewährt?

Tabelle 2: Kriterien zur Bewertung der Institutionalisierung reflexiver Arrangements 
Die erarbeiteten Kriterien werden nachfolgend im Rahmen einer Fallstudie in praxi an der Institutionalisierung von Reflexivität gespiegelt.

\section{Forschungsmethodisches Vorgehen}

Dieser Aufsatz gründet auf dem methodologischen Fundament des evolutorischen Institutionalismus. In Beiträgen dieser Art wird versucht, die Modernisierung von Unternehmen evolutorisch zu beschreiben - komplexitätstheoretisch (vgl. Kirsch/Seidl/van Aaken 2010), sozioökonomisch (vgl. Moldaschl 2015) oder auch biologistisch (vgl. Rabmeyer 2005), mit Mechanismen wie blinder Variation und selektiver Retention (vgl. Campbell 1960). Andere nähern sich dem Untersuchungsgegenstand ex negativo, indem sie institutionalistische Elemente und Prozesse identifizieren, die organisationale Einzigartigkeit und Modernisierung erschweren - so etwa „institutioneller Isomorphismus“ (vgl. DiMaggio/Powell 1983), der Angleichungstendenzen in organisationalen Feldern beschreibt, „organisationale Pfadabhängigkeit" mit Lock-in- und Rückkopplungseffekten (vgl. Koch 2009; Sydow/ Schreyögg/Koch 2009) oder auch „organisationale Routinen“ (vgl. Nelson/Winter 1982). Doch steht hier nicht die Institutionalisierung lernhemmender bzw. -fördernder Umwelten im Fokus, sondern die Institutionalisierung des Lernens selbst. Der Argumentationsduktus zeigt sich eher in prozessualer denn modellhafter Gestalt. So auch Raisch/Hargrave/van de Ven (2018), die organisationale Lernprozesse evolutorisch als „Lernspirale“ nachzeichnen und dabei zwischen Phasen der Konvergenz („learning by testing“) und Divergenz (,learning by discovery“) unterscheiden. Gemeinsam ist letztlich all diesen Konzeptionen, dass dem Zeitverlauf eine besondere Bedeutung zukommt.

\subsection{Referenztheoretisches Fundament: Theorie Institutioneller Reflexivität}

Das Konzept Institutioneller Reflexivität wurde deshalb ausgewählt, weil es mit seiner sozioökonomischen Begründung (vgl. Moldaschl 2015) besonders geeignet erscheint, die Widersprüche, die im untersuchten Feld in vielen Ansätzen thematisiert werden, auf eine konsistente Weise zu behandeln. Das betrifft zum einen die eben angesprochene Dimension des Lernens als Institutionenwandel, der als Dialektik beschrieben wird. Die Dialektik wird darin gesehen, dass betriebliche Organisationen auf Wiederholungen von Praktiken bauen müssen („Routinen“ bei Nelson/Winter 1982), dass aber diese Routinen in Raum und Zeit bzw. im situativen und zeitlichen Kontext nie vollkommen sind. Lernen wird daher in diesem Ansatz als Fähigkeit beschrieben, sich kritisch bzw. distanziert mit diesen Regeln zu befassen und aus ihrer Kontextunangemessenheit abzuleiten, welche Regeländerungen den erkannten anderen situativen und zeitlichen Bedingungen besser entsprechen könnten. Wobei Fähigkeit selbst auf diese institutionalistische Weise definiert wird als „institutionelles Vermögen“ sich zu distanzieren, seiner bisherigen Identität nicht verhaftet zu sein. Fähigkeit wird hier also als Potential verstanden, welches das verfügbare Set von Distanzierungspraktiken oder -routinen beschreibt. Die grundlegende Dialektik, mit der sich dieser Ansatz befasst, formuliert sich daher wie folgt: Wenn schon Routinen unverzichtbar und die Basis des Leistungsvermögens kollektiver Aktivitäten sind, dann besteht die paradoxe Herausforderung darin, Regeln gegen das Einrasten von Regeln zu entwickeln und zu implementieren (vgl. Moldaschl 2005a, 175). Typischerweise werden dann Regeln bzw. Routinen (das lässt sich hier synonym behandeln) beschrieben, die den einzelnen Akteur auffordern, die situative Angemessenheit der von ihm genutzten oder befolgten Regel zu 
prüfen - und wie dies ggf. zu erfolgen hat. Was in vorliegenden Ansätzen meist als sich widersprechende Erfordernisse von Stabilität und Wandel formuliert wird, erhält hier also die Fassung von auf sich selbst angewendeten Routinen, Regeln, Praktiken, Institutionen. Im Unterschied zu dem in den Natur- und Technikwissenschaften gebräuchlichen Begriff der Rekursivität, bezeichnet Reflexivität eine verständige Rückbezüglichkeit, kann also nicht in rein technischem Sinne gebraucht werden, und bezieht sich damit auf die Sinndimension menschlicher Praxis. Hier gibt es klare Parallelen zur „Beobachtung zweiter Ordnung“ (vgl. Moldaschl 2006, 20) im systemtheoretischen Denken. Auch sie hat immer einen Sinnbezug, der in der institutionellen Reflexivität von zentraler Bedeutung ist.

Außerdem schlägt der Ansatz damit auch eine grundsätzliche Unterscheidung von Regeln und Ressourcen vor. Damit wird zumindest ein Teil jener Beliebigkeit überwindbar, der sich in der Diversität jener Ressourcenansätze („Resource-based View“, „Knowledgebased View“, „Relational View“) wiederfindet, aus denen sich die „Capability View“ entwickelt hat. Im Ansatz der institutionellen Reflexivität ist es nicht einfach das „Genom“ der Routinen einer Organisation, das ihre Strategiefähigkeit ausmacht, sondern ein bestimmter Typus von Regeln und Routinen, der auf eigene, spezielle Weise Gebrauch von den besonderen Ressourcen einer Organisation macht (z.B. von ihrem „Symbolkapital“, vgl. Moldaschl 2011, 35). Damit ist es also nicht einfach diese oder jene Ressource (Wissen, „Skills“, Beziehungen), welche das Erfolgspotential einer Firma beschreibt, sondern der sinnhafte Umgang damit, zu dem diese Organisation fähig ist.

\subsection{Forschungsdesign}

Das forschungsleitende Erkenntnisinteresse erfordert eine interpretative Rekonstruktion von Sachverhalten und ihrer kausalen Zusammenhänge und verlangt damit einen qualitativen Forschungsansatz. Denn „[e]s ist unmöglich, eine Institution ohne den historischen Prozeß, der sie heraufgebracht hat, zu begreifen“ (Berger/Luckmann 2004, 58). So eignet sich qualitative Sozialforschung insbesondere (a) bei komplexen Ausgangssituationen wie dieser, (b) wenn der Historie und dem Kontext besondere Bedeutung zukommt, (c) eine unklare Kausalität vorliegt und (d) Kreativität in der Fragestellung gefordert ist (vgl. Wrona 2005, 18). Einer interpretativen Rekonstruktion sozialer Handlungssysteme sollte mit äußerster Sorgfalt, einer gewissen Offenheit und Interdisziplinarität für Erklärungsalternativen begegnet werden, im Sinne Feyerabends (1986): theoriepluralistisch. Dass mit rein quantitativen Studien zu institutioneller Reflexivität, besonders vor dem Hintergrund komplexitäts- und evolutionstheoretischer Annahmen, Aussagen zur Wirksamkeit einzelner Arrangements nur begrenzt möglich sind, konnte bereits gezeigt werden (vgl. Jain et al. 2016). Folglich wird den kulturell-handlungsleitenden Aspekten organisationaler Praxis kein unwesentlicher Erklärungsgehalt für die Analyse von Handlungssystemen beigemessen, weshalb sich die Empirie dieses Forschungsvorhabens auch fallanalytisch - rekonstruktiv und fallbegleitend - gestaltet. Denn nach Yin (2003, 2) eignen sich insbesondere Fallstudien, um die „holistic and meaningful characteristics of real-life events - such as (...) organizational and managerial processes“ ${ }^{\mathrm{zu}}$ erhalten. Weil Fallrekonstruktionen nicht im Modus der Hypothesenbildung bzw. -überprüfung gedacht werden sollten, handelt es sich bei diesem fallanalytischen Forschungsdesign eher um einen offenen Forschungsansatz. Die Systematisierung, Kategorisierung und Interpretation der gewonnenen Informationen wurde iterativ mit dem Fortschritt der Analyse modifiziert und erweitert, im Sinne eines zirkulären Forschungsprozesses (vgl. Flick 2012, 126 ff.). 
Das Sampling der Fallstudie wurde auf Basis theoretischer Überlegungen durchgeführt (vgl. Flick 2012, 158 ff., Meyer/Reutterer 2007, 241). Das zu untersuchende Unternehmen sollte nach Möglichkeit (a) in besonderer Weise mit überlebensnotwendigen Veränderungserfordernissen konfrontiert werden, also ein eher dynamisches Umfeld aufweisen, sodass reflexives Handeln nicht mehr dem Zufall überlassen werden darf; (b) sich als (zumindest einer der) Technologieführer seiner Branche verstehen, womit damit eher Kreativität denn Imitationstalent im Innovationsprozess erforderlich ist; (c) mehr als 500 Mitarbeiter beschäftigen und somit als „typisches“ Großunternehmen bezeichnet werden dürfen, da in internationalisierten Großunternehmen tendenziell eine Vielzahl an potenziell reflexiven Institutionen erwartet werden kann - und schließlich; (d) vom Forschenden (auch höher frequentiert) persönlich erreicht und dadurch eingehend untersucht werden können. In der engeren Auswahl standen zunächst acht Unternehmen unterschiedlichster Branchen, welche die oben genannten Kriterien erfüllten und in den Ländern Schweiz, Deutschland oder Österreich beheimatet waren. Nach einigen Telefonkonferenzen mit den Unternehmen wurde das beforschte Unternehmen schließlich ausgewählt, nicht zuletzt, weil die Kommunikation eine besonders vertrauensvolle Zusammenarbeit erwarten ließ und der Zugang zu internen Informationen nicht nur als eine ermöglichende Grundlage, sondern auch als wichtiges Gütekriterium qualitativer Forschung verstanden wird. Bei der zu erwartenden Komplexität ist eine tiefgreifende Analyse nur auf dieser Basis möglich.

\subsection{Analytik und Datenerhebung}

Im Rahmen der Fallstudie wurde mit der Analytik Institutioneller Reflexivität nach Moldaschl (2011, $40 \mathrm{ff}$.) in drei Schritten untersucht, ob und wie Reflexivität, in welcher Form, kontextangemessen und wirksam institutionalisiert ist und welche Folgen sich damit einstellen. Alternativ zu Schirmer/Knödler/Tasto (2012), die anhand des Konzepts der institutionellen Reflexivität einzelne Innovationsprozesse in Unternehmen untersuchten, fand die Analytik hier an institutionalisierten Regeln, Verfahren, Einrichtungen oder ganz allgemein Managementinstrumenten in einem einzelnen Unternehmen Anwendung.

Doch zunächst wurde das ausgewählte Unternehmen mittels unternehmensgeschichtlicher Aufarbeitung seiner Entwicklung, u.a. anhand maßgeblich prägender Ereignisse, Attribute, Kulturmerkmale und relevanter Kontextspezifika eingehend beleuchtet. Als Quellen dienten dabei u.a. Unternehmensarchive, Presseartikel, wissenschaftliche Publikationen, Konjunkturanalysen, Statistiken, Geschäftsberichte, Sonderpublikationen und Festschriften der Unternehmen, Börsenentwicklungsreports, Nachhaltigkeitsberichte, Handelsregistereinträge, Patentdatenbanken, aber auch Produkte, Märkte oder Marketingkampagnen bzgl. Personalakquise und Unternehmensimage. Das Ziel dieser Voranalyse wurde darin verstanden, Einblicke in die Gewordenheit unternehmensspezifischer Praktiken wie auch in „Entscheidungssemantiken und ihre direkten wie indirekten Folgen“ (Plumpe 2003, 151) zu erlangen. Das schafft nicht nur Vertrautheit mit der zu untersuchenden Organisation, sondern eröffnet dem Forscher auch die Möglichkeit, in den Interviews gezielt an prägenden, unternehmensgeschichtlichen Ereignissen anzuknüpfen.

Im Anschluss daran wurde (erstens) identifiziert, welche potenziell reflexiven Institutionen im Unternehmen Anwendung finden. Mehrere Workshops und Telefonkonferenzen mit den Ansprechpartnern im Unternehmen schufen zunächst ein einheitliches Verständnis über das wissenschaftliche Erkenntnisinteresse sowie das datenschutzrechtliche und organisatorische Vorgehen im Forschungsprojekt. Erstaunlicherweise konnten zunächst kaum 
institutionalisierte Praktiken identifiziert werden, welche die genannten Kriterien erfüllen. Das mag an ihrer „weichen“ Institutionalisierung liegen. Bogumil et al. (vgl. 2016, 78) erkannten darin sogar ein förderliches Moment für das Ausmaß der tatsächlichen Reflexivität in diversen Verfahrensweisen der öffentlichen Verwaltung. Außerdem wohnt dem Unternehmen grundsätzlich wenig Prozesshaftigkeit inne, wie sich im Laufe der Untersuchung noch zeigen sollte. Jedenfalls wurden die Interviewpartner aufgrund der (noch) fehlenden Untersuchungsobjekte vorerst zum Gespräch über ein großes Digitalisierungsprojekt des Unternehmens eingeladen, in das nicht nur alle produktnahen Abteilungen involviert waren, sondern dem auch reichlich Aufmerksamkeit zuteil war. So wurde die Auswahl geeigneter Gesprächspartner für die Suche nach den eigentlichen Untersuchungsobjekten kaum eingeschränkt. Erst allmählich konnte das Innovationsmanagement samt flankierender Aktivitäten als institutionelles Arrangement, das im Wesentlichen nach „alternativen Zukünften“ (vgl. Moldaschl 2011, 41) sucht (hier konkret im Bereich des Technologie- und Produktportfolios), identifiziert und schließlich beforscht werden. Das Digitalisierungsprojekt diente fortan nur noch als eisbrechende Gesprächseröffnung und allseits verständlicher Grund für die Einladungen zu den Interviews, die bis auf eine Ausnahme entgegenkommend angenommen wurden.

Im nächsten Schritt wurde (zweitens) die bis dato gebräuchliche Institutionenanalyse erweitert. Die ausgewählten (potenziell reflexiven) Managementinstrumente wurden nicht nur anhand der Kriterien in Tabelle 1 auf den tatsächlich realisierten Grad an Reflexivität bewertet, der erst durch die Art und Weise ihres Gebrauchs entsteht und nicht unwesentlich vom „Spirit der Organisation“ abhängt, sondern auch auf die Art und Weise ihrer Institutionalisierung und der Interdependenz beider. Dazu wurden 17 leitfadengestützte Experteninterviews mit Mitarbeitern aus unterschiedlichen produkt- bzw. marktnahen Abteilungen und Hierarchieebenen geführt, die im Entferntesten in eine der ausgewählten (potenziell reflexiven) Institutionen involviert sind, waren, sein werden oder aber über kontextrelevantes Wissen dazu verfügen. Die damit provozierte Perspektivenpluralität erschwerte zwar die Auswertung der erhobenen Informationen, wie die umfangreiche Ausführung der Fallstudie noch verdeutlichen wird, verringerte jedoch auch die Wahrscheinlichkeit interpretativer Verzerrungen aufgrund mangelhafter Durchdringung der Sachverhalte.

Der Gesprächsverlauf orientierte sich an einem Interviewleitfaden. Es wurde versucht, „Fragen mit narrativer Generierungskraft“ zu stellen, um dadurch die Antworten weitgehend unbeeinflusst zu erhalten (vgl. Liebold/Trinczek 2009, 36). Dadurch entstand ein erzählstimulierender Raum für eigene Interpretationen der Interviewpartner, der Zugang zu ihrer erlebten Wirklichkeit ermöglichte, u.a. was Sinnzuschreibungen und die Legitimation des eigenen Handelns betrifft. Mit diesem offenen, methodischen Verfahren ließen sich vor allem „komplexe Wissensbestände“ rekonstruieren (vgl. Liebold/Trinczek 2009, 35). Rekonstruktive Sozialforschung setzt voraus, dass die Beforschten „ihr Relevanzsystem und ihr kommunikatives Regelsystem entfalten können und auf diesem Wege die Unterschiede zum Relevanzsystem der Forschenden überhaupt erst erkennbar werden “ (Bohnsack 2014, 23). Durchschnittlich dauerten die Interviews 70 Minuten (von 32 bis 151 Min.) und konnten bis auf eines (Videokonferenz), persönlich und vor Ort in ungestörter Atmosphäre durchgeführt werden. Selbst externe Berater des Unternehmens erklärten sich zur Teilnahme an den Interviews bereit. Der Autor durfte überdies als passiver Beobachter in einer zweimal jährlich stattfindenden Großbesprechung teilnehmen und sich damit einen leben- 
digen und weitegehend natürlichen (wobei Einflüsse durch die Anwesenheit des Forschers nicht ausgeschlossen werden können) Eindruck über die Diskussions- und Entscheidungsprozesse im zu untersuchenden Milieu verschaffen. Eine primäre Onlineumfrage $(n=6$; qualitativ; hauptsächlich offene Fragestellungen $)^{1}$ half ferner, Eindrücke über spezifische Kulturmerkmale des Unternehmens aus Sicht neuer Mitarbeiter und Praktikanten einzufangen, die sich dem Bewusstsein langjähriger Mitarbeiter in der Regel entziehen. Die gegenwärtige Atmosphäre konnte mit einer qualitativen Analyse von zwei sekundären Mitarbeiterbefragungen der letzten Jahre beleuchtet werden. Eine davon zu den Arbeitsbedingungen im Unternehmen $(n=237$; rein quantitativ; standortumfassende Vollerhebung; standardisierte Onlinebefragung mit Antwortskalen; ausschließlich geschlossene Fragen). Die andere zu den Innovationsaktivitäten $(\mathrm{n}=10$; Stichprobe hierarchie-übergreifend, Fokus auf Mitarbeiter mit Schlüsselfunktionen in der Produktinnovation; strukturierte Interviews mit offener Einstiegs- und Abschlussfrage, jedoch hauptsächlich geschlossene Fragen mit Antwortskalen), beide kostenpflichtig beauftragt und durchgeführt von externen Beratungsunternehmen.

Um ein Bild von den propagierten Zwecken, wie auch dem agitierten Wertehimmel des Unternehmens zeichnen und den Kontrast zur gelebten Praxis herausfiltern zu können, wurden darüber hinaus über 100 relevante Dokumente (u.a. Presse-, Internet- und Intranetartikel, Geschäftsberichte, Strategiepapiere, Produkt- und Prozesspräsentationen und Besprechungsprotokolle) einer manuellen qualitativen Inhaltsanalyse unterzogen, die sich an den einzelnen Managementtools orientierte - dem Kern der eigentlichen Untersuchung. Ein regelmäßiger Kontakt zu den Ansprechpartnern im Unternehmen, die über aktuelle Geschehnisse und Veränderungen berichteten, wie auch das Feedback nach einer tiefgründigen Analyse der empirischen Daten, konnten in die Forschung einfließen und verliehen der Fallstudie ein längsschnittliches Element.

Schließlich wurde (drittens) vor dem Hintergrund des gegenwärtigen Kontextes (der situativen Veränderungserfordernis) die Notwendigkeit der installierten Reflexivität beurteilt. Denn entgegen der landläufigen Auffassung - „je mehr desto besser“, kostet auch die regelgeleitete Revision Zeit und Geld, denn „Unternehmen verkaufen nicht Veränderungsvermögen (...), sondern immer noch Produkte und Dienstleistungen“ (Moldaschl 2011, 42). Außerdem birgt die Revision bestehender Regeln und Strukturen nicht nur die Gefahr, den Status-Quo zu verschlechtern, sie kann ein beträchtliches Maß an Unsicherheit und Widerstand unter ihren Akteuren erzeugen (vgl. Hallensleben 2016).

\subsection{Method(olog)ische Überlegungen zur Operationalisierung von Performanz}

Die geführten Interviews wurden teiltranskribiert und einschließlich aller zur Verfügung stehenden Dokumente softwaregestützt kodiert. Die Kodierungsstruktur untergliederte sich in interne (Aspekte des unternehmenskulturellen Settings) und externe Kontextbedingungen (Wettbewerbs- und Absatzsituation), Facetten des Ideengenerierungsprozesses, sowie in die untersuchten org. Arrangements des Innovationssystems, konkret in die generalisierbaren Auffälligkeiten ihrer reflexiven Ausgestaltung und Institutionalisierung. Diffizil gestaltete sich die Operationalisierung ihrer Wirksamkeit (Performanz). In zahlreichen quantitativen Innovations- und Modernisierungsstudien wird versucht, Performanz als ab-

1 Angeschrieben wurden dazu ( $\mathrm{N}=12)$ Mitarbeiter, die spätestens vor zwei Jahren am Standort eingestellt wurden. 
hängige Variable direkt und absolut zu messen. Ob im Forschungsfeld der „Ambidextrie“ (vgl. Gibson/Birkinshaw 2004; Lubatkin et al. 2006; Vrontis et al. 2017), dem „New Product Development“ (vgl. Kleinschmidt/Brentani/Salomo 2007, Mishra/Shah 2009, ${ }^{2}$ Pavlou/El Sawy 2011) oder zu „Absorptive Capacity“ (vgl. Lane/Salk/Lyles 2001; Lichtenthaler 2009; Lin/Chuang/Wei 2014) - sie wird fast vorschriftsmäßig über Likert-skalierte Einschätzungen der Mitarbeiter, vorrangig des Senior- und Top-Managements, erhoben. Doch mit dieser Operationalisierungsweise sind einige Restriktionen verbunden. Gemeint sind hier insbesondere: (a) Konstruktambiguität (Interpretationsspielraum): Probanden werden um Einschätzungen gebeten, die sich auf Attribute beziehen, welche sich keinen einheitlichen Maßstab teilen bzw. deren subjektives Verständnis starken Schwankungen unterliegen kann (Was ist innovativ, inkrementell oder radikal?); (b) Non-intentionale Verzerrungen: Die wahrgenommene Dominanz aktueller Ereignisse, fehlerhafte Erinnerungen oder Versuche, vergangene Verhaltensweisen zu verklären, können in retrospektiven Befragungen Erinnerungen verzerren (vgl. Golden 1997). Auch „Selektive Wahrnehmungen “ und der reduzierte bzw. erweiterte Informationsumfang aufgrund der funktionalen Rolle und Hierarchieebene der Probanden in der Organisation verzerren Beurteilungen („Anker- oder Self-Reference-Effekt“), wie auch der (unbewussten) überdurchschnittlichen Wahrnehmung der eigenen Leistung („Lake-Wobegon-Effekt“ oder „Bestätigungsfehler“); ${ }^{3}$ und (c) es muss davon ausgegangen werden, dass Einschätzungen durch intentionale Verzerrungen der Befragten manipuliert sein können, vor allem wenn der Erfolg von Produkten oder Organisationseinheiten beurteilt werden soll, die in deren Verantwortungsbereich liegen (Befangenheit). ${ }^{4}$ Probanden könnten auch (bewusst) versuchen, den normativen Erwartungen des Unternehmens zu entsprechen, entweder als Vorsichtsmaßnahme für den Fall von Rückwirkungen auf sie selbst oder weil sie sich verpflichtet fühlen, ihre Antworten am propagierten Wertehimmel des Unternehmens auszurichten („Organisationales Commitment“ und „Konformismus“) und es damit möglichst souverän repräsentieren.

Statt über standardisierte, Likert-skalierte „Performanz“ im erläuterten quantitativen Sinn, wird Wirksamkeit in dieser Untersuchung über von Glasersfelds (1992b) „Viabilität“ operationalisiert. Nach von Glasersfelds (1992b, 143) radikal-konstruktivistischem Argumentationsduktus müssen wir zunächst „die Vorstellung verwerfen, daß die Abbildung, die wir aufgrund unserer Erfahrung konstruieren, in irgendeinem Sinne eine Welt widerspiegelt, die unabhängig von uns existiert“. Das trifft insbesondere auf Institutionen zu, die weit weniger „objektive“ Gestalt annehmen als viele andere Untersuchungsgegenstände der Wirtschaftswissenschaften. Vor diesem Hintergrund argumentiert er, dass Organismen (hier übertragen auf Institutionen) Veränderungen nur überleben können, wenn sie „die dafür erforderlichen Eigenschaften bereits besitzen, bevor diese Situation oder Umweltveränderung auftritt“ (Glasersfeld 1992a, 81). Darin spiegelt sich die Denkfigur einer potenzialorientierten Forschungsperspektive wider, in der Potentiale an sich nichts bewirken, sich also der Wert von (u.a.) Ressourcen erst im Gebrauch bestimmt (vgl. Moldaschl 2007a, 357 ff.). Wenn von Glasersfeld (vgl. 1992b, 139f.) von „Viabilität“ statt

2 In diesem 13-seitigen Beitrag findet das Wort „Performance“ sogar 157-mal Verwendung.

3 Dass die Wahrnehmung von Führungskräften selbst bei objektiven Sachverhalten stark verzerrt sein kann, arbeiteten bereits Mezias/Starbuck (2003) heraus.

4 Baumeister $(1982,3)$ beschrieb die Tendenz zur selbstwertdienlichen Verzerrung des Urteilsvermögens als „self-serving bias“ wie folgt: „If an audience [hier z.B. aufgrund der Gefahr des Anonymitätsverlusts bei Umfragen] controls or dispenses one's potential rewards, one obtains the rewards by getting the audience to think favorably of oneself“". 
von „Anpassung“ spricht, dann weil er behauptet, dass etwas überlebt, weil und so lange es mit den einschränkenden Bedingungen seiner Umwelt fertig wird. ${ }^{5}$ Diese ermöglichenden Kausalzusammenhänge sind es auch, die es herauszuarbeiten gilt. Analog dazu sind Institutionen „viabel bzw. überleben, solange sie die Zwecke erfüllen, denen sie dienen, solange sie uns mehr oder weniger zuverlässig zu dem verhelfen, was wir wollen" (Glasersfeld 1992b, 141). „Wiederholung erzeugt und erhält somit die ,Viabilität` gesetzter Regularitäten“ (Glasersfeld 1992b, 142).

Was brächte es daher, den Nutzen angewandter Managementwerkzeuge skalenbasiert zu erfassen, wenn sich doch ihr Fortbestand auch individualstrategisch begründen lässt. Darin liegt die Krux sozialwissenschaftlicher Forschung: Eigennutzmaximierende Handlungsbegründungen werden nur selten auf Nachfrage offengelegt. Doch das „Wesen des Sozialen ist [nun mal] politisch“ (Moldaschl 2015, 149). Der Fortbestand institutioneller Arrangements korreliert also nicht per se mit dem Grad der Erfüllung propagierter Ziele. Damit eröffnet sich die Möglichkeit zur Ebenenunterscheidung, denn die Definition ist relativ, kann sich also auf das Streben nach „supra-normal profits“, der Reduktion von CO2Emissionen in Produktionsprozessen, wie auch dem Ausbau betrieblicher Gesundheitsförderung gegen Stress und Burn-out beziehen - in jedem der Fälle interessieren die Abweichungen zwischen den propagierten, von den Mitarbeitern interpretierten Zwecken institutionalisierter Arrangements (bzw. reflexiver Institutionen) und den tatsächlich realisierten Ergebnissen samt unbeabsichtigter Nebenfolgen. So gilt es den Sinn zu erfassen bzw. zu rekonstruieren, der den Handlungen der Akteure zugrunde liegt und so erst die Deutung von Regeln und die Identifikation bzw. den Umgang mit Ressourcen bestimmt, denn „[a]lles kann zur Ressource werden, durch ein Interesse, eine Sinngebung“ (Moldaschl 2011, 44). Dieser Sinn wird jedoch nicht über standardisierte Einschätzungen ihrer Protagonisten erhoben, sondern qualitativ und indirekt, d.h. über die Erfassung multiperspektivischer Interpretationen mittels Interviews, teilnehmender Beobachtungen oder auch qualitativer Inhaltsanalysen einerseits und der Erfassung realisierter Ergebnisse bzw. situativer Zustände (je nach Gegenstand quantitativ und/oder qualitativ) andererseits (und damit relativ). Denn das, was eine Organisation „lernt, wird eben deshalb beibehalten, weil es zu befriedigenden Ergebnissen führt" (Glasersfeld 1992a, 82).

\section{Fallstudie Sportiva AG}

\section{„...zum Erfolg verdammt!“ (Senior Manager, Interview)}

Das Unternehmen dieser Fallstudie pflegt eine äußerst angenehme, authentische und offene Art der Kommunikation. Die Mitarbeiter nahmen über alle Hierarchieebenen hinweg weitgehend ohne Vorbehalte an den Interviews teil und stellten überdies selbst vertrauliche Dokumente ohne geäußerte Bedenken zur Verfügung. Wer schon einmal in großen Unternehmen zu heiklen Themen forschte, wird das vielleicht zu schätzen wissen. Da den kulturell-handlungsleitenden Aspekten kein unwesentlicher Erklärungsgehalt für die spezifische Installation und Anwendung potenziell reflexiver Institutionen beigemessen wird und auch

5 Er hob außerdem hervor, dass Verhaltensweisen keineswegs ausschließlich auf den „,mechanistischen Prozeß` der natürlichen Auslese“ zurückzuführen sind, also die japanische Makakenäffin Imo auch ohne das Reinigen ihrer Süßkartoffeln in Wasser überleben würde (vgl. Glasersfeld 1992a, 84), wie auch Unternehmen ohne die Existenz etlicher Institutionen. Ihre Persistenz erklärt sich damit ausleseunabhängig, das heißt z.B. über individual-psychologische Motive oder systemische Funktionalität. 
ihre Genese rekonstruiert bzw. erklärt werden soll, ist es notwendig, zunächst das Unternehmen und seine kontextuelle Einbettung etwas genauer zu beschreiben, als es für solche Fallstudien üblich ist. Schließlich sieht die zugrundeliegende Analytik auch eine Berücksichtigung der Intensität organisationaler Lernaktivitäten vor dem Hintergrund situativer Erfordernisse vor.

\subsection{Kontext und Spezifika}

Die Sportiva ${ }^{6}$ blickt auf eine jahrzehntelange Unternehmenshistorie zurück und beschäftigt Mitarbeiter im unteren vierstelligen Bereich. Das Unternehmen hat seine Wurzeln im mitteleuropäischen Raum und stellt Sportartikel für den Endverbrauchermarkt her. Die Unternehmensorganisation ist multi-divisional strukturiert, im Wesentlichen nach Sportarten. Alle Produkte des Unternehmens werden in der Konzernzentrale entwickelt. Das Unternehmen ist stark internationalisiert und populär, nicht zuletzt aufgrund seiner Produktpalette, die mehrere Breitensportarten umfasst. Alle Produkte der Sportiva können zwar der Sportbranche zugerechnet werden, bedienen aber innerhalb dieser verschiedenartige Märkte und unterscheiden sich in der Expertise bzgl. ihrer Herstellungsverfahren, der verwendeten Materialien und des Aufbaus der Produkte teils drastisch. Das Unternehmen versucht, wie auch die Konkurrenz, möglichst viele Artikel zur Ausübung der jeweiligen Sportart anzubieten und kann deshalb als stark horizontal markengedehnt beurteilt werden.

\subsubsection{Unternehmensentwicklung und Marktanteile}

Etwa Mitte des letzten Jahrhunderts gegründet, ergänzte die Sportiva ihr Produktportfolio bald darauf um ein weiteres, vom bisherigen Produktsegment völlig unabhängiges Standbein. Durch den Zukauf spezialisierter Unternehmen erschloss die Sportiva zwar zunehmend weitere Märkte, wechselte indes aber auch mehrmals den Eigentümer. Wie ein Mitarbeiter berichtete, hat es auch Zeiten gegeben, „wo wir nicht wussten, ob es die Firma noch zwei Monate länger geben wird“ (Senior Manager, Interview). Im Anschluss an eine kurzweilige Durststrecke in den frühen 90ern durchlebte das Unternehmen dann mit einem bis heute unerreichten Produkterfolg üppige Jahre. Auch in den letzten zehn Jahren konnte das Unternehmen den Umsatz (bei teils stark schwankender Marge) um mehr als zehn Prozentpunkte steigern. Laut Umfragen ${ }^{7}$ hält das Unternehmen seine Marktanteile bei den Kernprodukten nun seit etlichen Jahren im weltweiten Vergleich mit den Wettbewerbern recht konstant bei etwas mehr als einem Viertel und behauptet damit einen Platz unter den besten drei der Branche. Abgesehen von den beiden Hauptkonkurrenten teilen

6 Ein Kunstname zur Wahrung der Anonymität des untersuchten Unternehmens. Des Weiteren wurden sämtliche Spezifika unter Beibehaltung der Verhältnismäßigkeit entschärft, sodass eine eindeutige Identifikation unmöglich, der Sachverhalt dabei aber nicht unangemessen verzerrt wird. Analog hierzu wurden die Interviewpartner lediglich als Manager oder Senior Manager ausgewiesen. Die Nennung ihrer Funktion oder einer differenzierteren Hierarchieebene ließe aufgrund der Größe des untersuchten Feldes sonst Rückschlüsse auf ihre Identität zu. So kann gewährleistet werden, dass selbst bei erhärteten Mutmaßungen zur Urheberschaft von Aussagen mindestens eine Alternative nicht ausgeschlossen werden kann. Eine Ausnahme bildet dabei der Innovationsmanager, dessen Zustimmung zur expliziten Erwähnung seiner Rolle, wie auch zu den damit verbundenen Hintergrundinformationen und subjektiven Urteilen explizit eingeholt wurde.

7 Für eine fundierte Einschätzung der gegenwärtigen Anteile am Marktvolumen und der Außenwahrnehmung der Marke konnten (großangelegte) repräsentative und unabhängige Marktumfragen der letzten Jahre ausgewertet werden. 
sich die restlichen Wettbewerber die wenigen verbleibenden Marktanteile. Obwohl diese Zahlen für sich sprechen, schien sich aufgrund der schleichenden Konsolidierung der Branche in den letzten beiden Jahrzehnten, welche zahlreichen Wettbewerbern drastische Anteilsverluste oder gar die Existenz kostete und auch demütig von den Mitarbeitern als eine „irrsinnige Marktkonzentrierung“ wahrgenommen wurde, eine vorsichtig bis misstrauische Haltung gegenüber der zukünftigen Unternehmensentwicklung einzustellen.

\subsubsection{Gegenwärtige Atmosphäre und unternehmenskulturelle Aspekte}

Aus den Gesprächen ging hervor, dass sich der Großteil der befragten Mitarbeiter zwar mit dem Unternehmen und seinen Produkten identifiziert - was vermutlich auch an der (intrinsisch-motivierenden) Sportbranche selbst liegen mag - das Engagement bei den Mitarbeitern jedoch seit einigen Jahren stetig abzunehmen scheint:

„Wenn ich jetzt immer noch, nach wie vor, mit 100\% dabei bin, beim Job (...) dann waren es früher wahrscheinlich 130\%." (Manager, Interview)

Nun könnte womöglich eine zu hohe Arbeitsbelastung für den Verdruss der Mitarbeiter ursächlich sein. Ein Blick auf die Entwicklung der betriebswirtschaftlichen Kennzahlen in den letzten Jahren entkräftet jedoch die Vermutung, es läge an einer quantitativen Überforderung, da proportional zum Umsatz auch die Anzahl der Mitarbeiter wuchs. Auch in einer standortumfassenden Mitarbeiterbefragung vor einigen Jahren wurde die quantitative Arbeitsbelastung von den befragten Mitarbeitern als akzeptabel und homogen empfunden. Erst bei differenzierterer Betrachtung fällt auf, dass diese Umfrage nicht zwischen den einzelnen Funktionsbereichen im Unternehmen unterschied. In den Interviews zeigte sich schließlich, dass außerhalb der Forschungs- und Entwicklungsabteilung (F\&E) durchaus eine hohe Belastung wahrgenommen wird, und das, obwohl die Anzahl der Mitarbeiter innerhalb der F\&E sowie deren finanzielle Mittel - um ein ähnliches Größenverhältnis, wie die Gesamtmitarbeiteranzahl stieg - reduziert wurden. Das mag auch erklären, weshalb die anderen Mitarbeiter die Arbeitsbelastung besonders im Hinblick auf die „Generierung neuer Ideen “ als hinderlich empfinden:

„Man hat nie Zeit für solche Sachen (...) man muss sich die Zeit schaffen." (Manager, Interview)

Damit sind es die Mitarbeiter in produkt- bzw. marktnahen Abteilungen außerhalb der F\&E, deren Zufriedenheit im Vergleich weit geringer eingestuft werden sollte. Sie beklagen außerdem eine mangelnde Wertschätzung. Einige exemplarische Aussagen sollen die gegenwärtige Stimmung in groben Zügen widerspiegeln:

„Wir versuchen halt, das ist eher so das Intrinsische, dass wir uns selber halt motivieren. Aber irgendwann mal ist halt auch die Decke erreicht. Du kannst dich nicht Jahre selber, weil da halt einfach nix kommt, nix. Das ist schwierig. " (Senior Manager, Interview)

„Was mir leider auffällt, dass viele Mitarbeiter so ein Wurstigkeitsgefühl entwickeln." (Senior Manager, Interview) 
„...ich würde versuchen erstmal wieder (...) so 'ne Art Kultur reinzubringen, weil ich finde, das ist so ein bisschen verloren gegangen über die letzten zwei, drei Jahre, also dieses Miteinander und nicht teilweise Gegeneinander." (Manager, Interview)

Doch sind es nur die als zwanghaft empfundene Suche nach Neuem und das vergebliche Streben nach Würdigung, die außerhalb der F\&E für Unzufriedenheit sorgen? Denn anders als erwartet, empfinden die Mitarbeiter Prozesse und Regeln als „locker“ bzw. „nicht extrem sklavisch“, die Zusammenarbeit als „kollegial“, die „Wege als kurz“ und die „Hierarchie als flach“. Erst allmählich gab sich aus den Interviews zu erkennen, dass die Hierarchie relativ, d.h. nur in Bezug auf den nächsten Vorgesetzten als flach empfunden wird. Sie erfährt erst ab einer gewissen Ebene eine sprungfixe Zunahme, bei der sich die Entscheidungsprozesse stark konzentrieren. Ab dieser Ebene könne man „nicht mehr locker diskutieren“, ...

„...sind die Meetings natürlich dementsprechend auch gebremst.“ (Manager, Interview)

„...ist immer eine gewisse Hemmschwelle da (...) das merkt man in den Meetings auch." (Manager, Interview)

Dass Hierarchie bei der Generierung neuer Ideen eine hemmende Wirkung hat, konnte bereits vielfach gezeigt werden (vgl. u.a. Jain/Manger 2016 oder Keum/See 2017). Sie mag zwar den Zusammenhalt der Gruppe stärken, doch weil Entscheidungen ohne das Beisein dieser Hierarchieebene keine Gültigkeit beanspruchen können und selbst die gesamte, übereinstimmend als flach empfundene Hierarchie darunter ausgehebelt werden kann, wird ihr damit auch die gerade im frühen Innovationsprozess notwendige Autonomie entzogen. Auch die Fehlerkultur des Unternehmens wurde von der F\&E weit liberaler beschrieben als von den restlichen Abteilungen, in welchen dagegen Druck empfunden und Raum vermisst wurde, in dem gescheitert werden darf:

„Wenn du keine Fehler machst, dann bist du nicht weit genug gegangen." (Senior Manager FơE, Interview)

„Wir sollen sogar an gewissen Sachen scheitern, weil sonst wären wir nicht ans Limit gegangen." (Manager FóE, Interview)

Aus dieser Herangehensweise könnte man schließen, die Sportiva sei ein risikoaffines, entscheidungsfreudiges und pionierstrategisches Unternehmen. Vor diesem Hintergrund verwundert es, dass die interviewten Mitarbeiter dieser Vermutung eher widersprachen. Einige beklagen Entscheidungsschwäche, einige Risikoaversion und andere erkennen sogar eine „Gap“ zwischen dem vorhandenen Innovationspotenzial und seiner tatsächlichen Nutzung.

"Wir haben so viele gute Ideen und so früh. Und dann kommen wir nicht damit und dann sehen wir, dass genau damit die Mitbewerber kommen. " (Manager, Interview)

Empirische Belege für die Behauptung, das Unternehmen hätte eine zögerliche Haltung, ließen nicht lange auf sich warten:

„,Dem Ersten die Not, dem Zweiten der Tod und der Dritte erst das Brot.' Es nutzt nix, wenn wir die Ersten draußen sind, wenn der Markt noch nicht da ist. " (Senior Manager, Interview) 
Diese Einschätzung steht dem selbsterhobenen Anspruch der Innovationsführerschaft freilich entgegen, den das Unternehmen unter den Mitarbeitern zu teilen pflegt. Außerdem versteht sich das Unternehmen als „High-Performance Brand“. Dieses anspruchsvolle, wenn nicht sogar perfektionistische Selbstverständnis, ...

„...hat natürlich auch den Blick verstellt, auf das, was vielleicht die große Masse denkt, tut, möchte, braucht. Weil man eine ganz klare Bezugsgruppe hatte, und das waren die Profis." (Externer Berater, Interview)

Teilnehmende Beobachtungen zeigten, dass dieser hohe Anspruch auch bei der Auswahl von Ideen für neue Produkte selektierend wirkt. So wurden häufig selbst neue Ideen mit unbestrittenem Mehrwert unter direktem Verweis auf die Firmenphilosophie infrage gestellt:

„Wenn ich mich an der Zielgruppe orientierte (...) dann ist das natürlich auch was, was mich davor schützt, ins Mittelmaß zu rutschen." (Externer Berater, Interview)

Auch als die Mitarbeiter zur Vision des Unternehmens befragt wurden, antworteten sie schlagfertig: „Wir wollen Nr. 1 werden!“, wenngleich sie nicht wissen, wie es das zu bewerkstelligen gilt. Denn eine Strategie vermissen sie einstimmig:

„Ich denk für ein Unternehmen mit der Größe was wir haben, sollten wir eigentlich schon 'ne Strategie haben: Wo will man hin, was will man erreichen und wo liegt mein Fokus. " (Manager, Interview)

Die Ressorts der Sportiva werden als Profit-Center geführt und werden damit primär am erwirtschafteten Gewinn gemessen. Daraus resultiert womöglich auch die „Budget- und Profitgetriebenheit“, welche die Mitarbeiter in ihrem Alltag merklich begleitet. Investitionen werden vorrangig nach kurzen Amortisationsperioden beurteilt und weiche, z.B. „markenbildende Aspekte“ von harten „Break-Even-Berechnungen“ überlagert. Produkte müssen nach kurzer Zeit Profit generieren, sonst wird ihre Produktion eingestellt bzw. gar nicht erst aufgenommen:

„Wir sind ein budget-geführtes, budget-getriebenes Unternehmen. Bei uns geht sehr viel darum, am Ende des Jahres Budget zu erreichen. " (Senior Manager, Interview)

„Wir sind extremst zablengetrieben (...) wir müssen extremst auf die Kosten, auf die Profitabilität gucken. “(Senior Manager, Interview)

\subsubsection{Innovationserfordernis und Umfelddynamik}

Das Image der Marke wird laut vorliegenden Marktumfragen ${ }^{8}$ zwar durchweg positiv bewertet - sowohl in Bezug auf die Qualität, Preis-Leistung, wie auch technischer Innovation $^{9}$ - doch bleibt die Sportiva, bis auf Qualität und Preis-Leistung, in welchen sie mit der Bewertung ihrer Hauptkonkurrenten gleich zieht, in allen weiteren Bewertungskriterien hinter mindestens einem Konkurrenten zurück. Bei jungen Konsumenten wird die Sportiva im Vergleich zu ihren Hauptkonkurrenten sowohl in Bezug auf Qualität und technische

8 Der Name und das branchenspezifische Institut der Umfrage werden zur Wahrung der Anonymität des untersuchten Unternehmens nicht genannt.

9 Welche laut Umfrage mit Abstand die wichtigsten Kriterien bei der Markenpräferenz der Konsumenten darstellen. 
Innovation, wie auch in Bezug auf Coolness und Leidenschaft, durchweg als schwächste Marke eingestuft. Selbst bei der Attribuierung zum Branchenspezialist schließt sie in diesem Kundensegment das Feld von hinten ab. Nun lassen sich diese Ergebnisse auf verschiedene Weise interpretieren. Zunächst positiv, da die Sportiva in fast allen Dimensionen unter den besten drei rangiert, obwohl es noch weitere Wettbewerber gibt (wenngleich mit geringen Marktanteilen). Oder aber negativ, da der Markt im Wesentlichen von nur drei Teilnehmern bestimmt wird und die Leistung vor diesem Hintergrund weit schlechter beurteilt werden sollte.

Auch im Unternehmen selbst wird die Innovativität der Sportiva unterschiedlich bewertet. Das kann dem Umstand geschuldet sein, dass sich nun schon seit längerer Zeit keiner der drei führenden Wettbewerber sichtlich von den anderen abzusetzen vermag, woraus wohl auch die ambivalenten Bewertungen entstanden. Laut Aussagen der Mitarbeiter wird das Unternehmen außerdem nach innen, also bezüglich Prozesse, unterstützender Softwaresysteme, Abläufe und der Infrastruktur als äußerst rückständig wahrgenommen. Nach außen hingegen beurteilen die Mitarbeiter das Unternehmen als besonders fortschrittlich. Es wird darüber hinaus als branchenbedingte Herausforderung wahrgenommen, sich immerfort vom Wettbewerber differenzieren zu müssen:

„Das prinzipielle Problem ist: Es kocht jeder mit denselben Zutaten und mit denselben Verfahren dieselbe Suppe und jetzt muss man sich irgendwie unterscheiden voneinander." (Manager, Interview)

„We are in a market suffered from sameness. " (von Senior Manager zitierter Redner auf einer Branchenkonferenz, Interview)

Mit dem branchenüblichen Innovationsverhalten, vermittelt über die Erwartungen der Konsumenten und Händler sowie der nachfrageinduzierten Verhaltensadaption anderer Marktteilnehmer, wird die Notwendigkeit begründet, regelmäßig neue Produkte entwickeln zu müssen:

„Natürlich setzt einen das in 'ner gewissen Weise unter Druck, diese zwei Jahre. Das ist so ein bisschen branchenüblich oder [Sportiva]-üblich (...) Natürlich sind wir irgendwo getrieben, weil der Markt nach Neubeiten sucht. Neubeiten lassen sich besser verkaufen, bessere Margen entsprechend erzielen. Und deshalb ist es schon für uns wichtig, dass wir dem Anspruch nachkommen, Innovationsfübrer zu sein und zu bleiben." (Senior Manager, Interview)

Im Unternehmen besteht weitgehend Einigkeit über diesen zwei(bis vier-)jährigen Innovationszyklus. Legitimiert als normative, exogene Gesetzmäßigkeit der Branche, entfaltet er seine Wirkung als indiskutables (weil unauflösbares) Druckmittel und wird auch „absolut, volles Rohr, voll! [sic!]“ (Senior Manager, Interview) als solches, wie auch in seinen Folgen, wahrgenommen und durch alle Hierarchieebenen delegiert. Dieser Zyklus scheint tief in den Köpfen der Entwickler verinnerlicht und zeigt institutionalisierte Verhaltensanpassungen, wie einem Mitarbeiter auffällt:

„Die sind schon so gepolt, unsere Leute, dass sie dann mit irgendwas kommen müssen und wenn es nur Brösel sind, die man reinstreut..." (Manager, Interview)

In der Argumentationsfigur des soziologischen Neoinstitutionalismus werden solche Angleichungstendenzen innerhalb eines organisationalen Feldes mit „mimetischer Isomor- 
phie“ erklärt. DiMaggio und Powell bezeichnen damit nachahmendes Verhalten als Reaktion auf Ungewissheit und kausale Ambiguität (vgl. DiMaggio/Powell 1983, 151 f.). So entstanden die branchenweiten homogenen Innovationszyklen vermutlich erst, weil es den Unternehmen als zu risikoreich schien - entgegen einzelner Wettbewerber - auf eine regelmäßige Produkterneuerung zu verzichten. Dadurch begünstigt, institutionalisierte das technik-dominante und produkt-lastige Innovationsverständnis im Unternehmen bzw. in der ganzen Branche offensichtlich zu einer beständigen Gegebenheit und entwickelte allmählich auch eine Eigendynamik:

„Wir entwickeln was und dann fragen wir Leute und wollen rausfinden, ob da ein "Need' dafür da ist und natürlich sehen wir den ,Need" Wir wollen ihn sehen!" (Senior Manager, Interview)

Die produktnahen Mitarbeiter sehen sich Erwartungen ausgesetzt, zu deren Erfüllung sie aber nicht in der Lage sind. Auch hier scheint sich der mimetische Mechanismus institutioneller Isomorphie bis auf die Wahrnehmung der Mitarbeiter durchzuschlagen (vgl. DiMaggio/Powell 1983). Es wird ein vom Markt aufgebürdeter Zwang zu regelmäßiger Innovation empfunden, dessen Zyklus jedoch zu kurz ist, um angemessene Ergebnisse zu erzielen:

„Die letzten größeren Innovationen sind jetzt schon länger her. Daran leidet sicherlich die gesamte Branche. Und dann versucht man halt durch kosmetische Tricks die Konsumenten dazu zu bewegen [sich ein neues Produkt] zu kaufen. Also da ist sicherlich eine gewisse Notsituation da. " (Manager, Interview)

Doch trotz ausbleibender technischer Neuerungspotenziale sehen sie sich zur regelmäßigen Ausbringung neuer Produkte veranlasst. Die Mitarbeiter sprechen von „Scheininnovationen “. Sie lieben zwar was sie tun, es fällt ihnen aber zunehmend schwer, stolz darauf sein. Es scheint, sie kämpften nicht gegen ihre Wettbewerber - in Gesprächen wurde über diese immer respektvoll geurteilt, wie es sich für „Sportsmänner“ gehört - sondern vielmehr gegen Scheininnovationen. Daraus entwickelten sich schließlich „kognitive Dissonanzen“10, wie folgende, in sich widersprüchliche Aussagen vermuten lassen:

„Man muss es deutlich machen: Das ist nicht, dass wir die Produkte nicht verbessern, aber [es] ist ein 400 Jahre altes Produkt (...) Wie viel kann ich da noch verbessern?" (Senior Manager, Interview)

„Sehr viel ist Bla bla (...) Das bedeutet nicht, dass die Produkte nicht besser sind, aber das, womit man es vermarktet, ist nicht unbedingt das, was es besser macht." (Senior Manager, Interview)

Offensichtlich bedarf diese auf Dauer angelegte Inkonsistenz sogar einer überindividuellen Konzeption, also eines analytischen Zugangs über eine höhere Aggregationsebene. Denn die marktinduzierten Arbeitsweisen stehen vielmehr im Widerspruch zum institutionalisierten Wertesystem (bzw. Identität) der gesamten Organisation. Gespräche mit den Ent-

10 Nach Festinger (1957) ein Zustand des inneren Konfliktes, der aus dem Streben des Menschen nach Widerspruchsfreiheit entsteht, wenn zusammenhängende Kognitionselemente, wie Meinungen, Überzeugungen oder Wünsche nicht in Einklang zueinander stehen. Diese Unvereinbarkeit wird i.d.R. als unangenehm empfunden und durch den Einsatz diverser Dissonanzreduktionsstrategien zu verringern versucht. 1975 erweiterte Irle die Theorie, indem er bereits vor Auswahlentscheidungen, also vor der eigentlichen Handlung, die Existenz kognitiver Dissonanzen unterstellt. 
wicklern, ausschließlich Physiker und Ingenieure, lassen einen hohen Anspruch an die Arbeitsergebnisse erkennen. Die Mitarbeiter messen ihre Leistung weniger am Absatz der Produkte, denn vielmehr am Grad der technischen Neuerung:

„Innerhalb von zwei Jahren kannst du die Welt nicht revolutionieren. " (Senior Manager, Interview).

„Die Verbesserungen sind so klein, dass der Kunde es nicht mehr spürt." (Senior Manager, Interview).

Doch der Markt stellt ihnen nicht genügend Zeit zur Verfügung, um die (selbst auferlegten) revolutionären Innovationen entwickeln zu können. ${ }^{11}$ Solche „mentalen und strukturellen Spannungen“ in Organisationen konzipierte Jochims (2010) als „organisationale Dissonanz“. Sie entsteht, wenn sich widersprechende Strukturen verfestigen, die das Überzeugungssystem der Organisation aus dem Gleichgewicht bringen und damit ihre Identität gefährden (vgl. Jochims 2010, 59 ff.). Organisationale Dissonanz löst jedoch nicht zwingend Dissonanzempfinden bei einzelnen Personen aus. Individuelle Lösungsstrategien hätten bei strukturellen Störungen ohnehin geringe Erfolgsaussichten. Sie zu etablieren, solange sie kollektiven Mustern entgegenstehen, wäre ein mühseliges Unterfangen (vgl. Jochims 2010, 65 ff.). Die Sportiva reagierte mit „Assimilation“ als Reduktionsstrategie auf die organisationale Dissonanz. Dabei wird die Störung als solche zwar irgendwann unverfälscht erkannt, daraufhin jedoch modifiziert, um wieder kollektive Harmonie einzustellen. Ähnlich auch Weick (1995), der diese integrative Leistung als Prozess des „Enactment - Selection - Retention“ konstruiert. So justierte die F\&E bzw. das Unternehmen schließlich ihren Fokus neu und überführte ihr technikdominantes Innovationsverständnis in ein gesamtheitlicheres, eines das u.a. auch marketingtechnische Aspekte einschließt. Die Mitarbeiter erkannten allmählich, dass ausbleibende (spürbare) technische Fortschritte durch eine entsprechende Vermarktung kompensiert werden können bzw. müssen, um der nachfrageinduzierten Forderung nach Innovationen nachkommen zu können und damit wettbewerbsfähig zu bleiben:

„Wir haben irgendwann aktiv vor ca. sieben Jahren (...) wo wir die Krise erreicht hatten, haben wir gemerkt, [bei unseren klassischen Produkten] sind die Verbesserungsmöglichkeiten so klein, wir müssen mehr in die Vermarktung. " (Senior Manager, Interview)

„....der Handel sagt dann: ,Ich kann den Kunden nur überzeugen, ein neues Produkt zu kaufen, wenn ich ein klares Argument hab, dass dieses Produkt besser ist, als das andere. Ich brauche eine Story'. Und diese Story bieten wir ihm!" (Senior Manager, Interview)

„Umso kleiner die Wirkung, umso mehr muss ich pushen. “ (Senior Manager, Interview)

Diese neue Sichtweise entbehrte jeglicher Zustimmung. Zahlreiche Interviews vermittelten den Eindruck, dass einige Mitarbeiter solchen marktwirtschaftlichen Facetten heutiger In-

11 Das Dilemma an radikalen Innovationen ist doch, dass der Seltenheitswert in der Natur ihrer Sache liegt. Erst weil sie einer Periode inkrementeller Veränderungen folgen, können sie als radikal wahrgenommen werden. Wenn jede Innovation radikal wäre, welche wäre dann eigentlich noch radikal? 
novationspraxis nur widerwillig Akzeptanz beimessen, nicht zuletzt, weil sie an der Arbeitsidentität der Ingenieursprofession kratzt:

"Ich bin ein strikter Gegner von den ganzen Scheininnovationen. Wenn wir was machen, dann soll das wirklich innovativ sein, neu sein." (Manager, Interview)

Der Übergang zu einer gesamtheitlicheren Produktmodernisierung stellte sich nicht ohne Komplikationen ein. So wurden fortan nicht nur mehrere Abteilungen in den Innovationsprozess eingebunden, auch die Verantwortung der Entwicklungsabteilung verteilte sich damit auf mehrere Organisationseinheiten:

„So, jetzt liegt es eben an uns mehr oder weniger: ,Ihr müsst jetzt die Story bauen'. Das ist für mich ein Alptraum. " (Senior Manager außerhalb der F\&E, Interview)

Dieser Wandel in der Arbeitspraxis der Sportiva war, wie die Interviews vermittelten, hauptsächlich negativ konnotiert. Ein Bindeglied schien jedoch diese Umstellung zu erleichtern: Ein legendärer Produkterfolg des Unternehmens aus den 90er Jahren, der mittlerweile sogar als Narrativ ${ }^{12}$ auftritt. Er fungiert bis heute nicht nur als Maßstab, sondern als inoffizielles Bestreben, es diesen Zeiten gleich zu tun. Gewissermaßen der Beginn einer neuen Zeitrechnung, die binär alles vor und nach diesem Triumph unterscheidet. Es ist auch heute noch ein wirkmächtiges "Sediment“ in der Wissensbasis des Unternehmens: ${ }^{13}$ „Weil das einfach 'ne Revolution war" (Senior Manager, Interview). Damit fungiert das Narrativ womöglich als Ersatz für die fehlende Strategie. Das geschilderte Innovationserfordernis lässt erahnen, welche Brisanz und welches Konfliktpotenzial jedwedem Versuch innewohnen, in die Innovationsaktivitäten der Sportiva einzugreifen, sie womöglich noch künstlich zu modernisieren und verbindlich zu institutionalisieren. Wie das dennoch geschah und welche Nebenfolgen sich damit einstellten, soll nun detaillierter herausgearbeitet werden.

Resümierend hinterlässt die Sportiva jedoch weder ein beratungsresistentes, veränderungsscheues, noch rigides oder pathologisch pfadabhängiges Bild. Im Gegenteil: Die Mitarbeiter sind intrinsisch motiviert, die Zusammenarbeit wird als kollegial beschrieben und die Hierarchie als flach. Nach Argyris/Schön (vgl. 2006, 127) erfüllt die Sportiva weitgehend die Leitvariablen einer „Modell I-Organisationswelt“, die „Doppelschleifenlernen“ begünstigen. Die interviewten Mitarbeiter wiesen ein hohes Maß an Selbstreflexion auf. Häufig hinterfragten sie unaufgefordert ihre Sichtweisen und suchten Fehler ganz selbstverständlich bei sich selbst.

\subsection{Das Innovationssystem der Sportiva als reflexive Institution(en)}

Im Fokus der Untersuchung stand zunächst das Innovationsmanagement als funktionale Organisationseinheit. Doch mit fortwährender Recherche nach reflexiven Institutionen

12 Häufig auch synonym für „Geschichten“, „(Meister-)Erzählungen“. Wobei dem Begriff terminologische Unschärfe zugeschrieben wird (vgl. Viehöver 2014, 76 ff. oder Perrin/Wyss 2016, 242). Narrative entfalten ein Thema, können dabei aber keinem singulären Autor zugerechnet werden. Sie ermöglichen die Filterung nach Relevanzkriterien und stiften damit Sinn und Ordnung (vgl. Schreiber 2015, $14 \mathrm{f}$.$) . Wolf (2002,29)$ versteht „Narrative (und damit auch den Akt seiner Realisierung, das Erzählen) als kulturell erworbenes und mental gespeichertes kognitives Schema“.

13 Siehe auch "Sedimentierung“ (vgl. Hedberg 1981) oder „Sedimentbildung und Tradition“ (vgl. Berger/Luckmann 2004, 72 ff.). 
(vermittelt als beiläufiges Interesse in den Interviews) zeigten sich allmählich weitere lose gekoppelte Instrumente, deren Zweck es ist, Innovationen zu fördern:

1. das Innovationsmanagement in persona,

2. „NeXt“, eine Innovations- und Ideenmanagementsoftware,

3. diverse Events wie Innovationstage, Kick-Off-Meetings und Brainstormings,

4. „Stage-Gate“, ein Idea-to-Launch-Prozess und

5. „Future Product“-Projekt, ein temporäres Technologie-/Produktentwicklungsvorhaben.

Die zusammenfallende Zweckausrichtung lässt kausale Verkettungen zwischen ihnen vermuten, weshalb sie hier auch zu einem Innovationssystem modelliert wurden. Das Innovationssystem der Sportiva zeigt sich aus diesem Blickwinkel nicht nur ganzheitlich gestaltet, indem es die zahlreichen Aspekte und vielschichtigen Phasen des Innovationsprozesses angemessen berücksichtigt, es ist außerdem speziell auf das Unternehmen, seine Produkte und Märkte zugeschnitten. So fördert es Aktivitäten zur kreativen Ideengenerierung mit regelmäßigen Veranstaltungen, unterstützt die Kommunikation und Ausarbeitung von Ideen mit einer Softwareplattform, strukturiert die Bewertung und Auswahl von Ideen, die weiterverfolgt werden sollen prozessual und ist in persona vertreten durch einen Innovationsmanager der neben der Beratung von Mitarbeitern nach neuen Technologien scoutet, „Open Innovation“ verstärkt und das Unternehmen außerdem in Netzwerktreffen vertritt - äußerst vorbildlich und zeitgemäß.

Doch wird es von den Mitarbeitern als institutionalisiertes Arrangement zur Kreativitätsförderung, zu starker Bürokratisierung bezichtigt? Schafft es durch seine vielschichtige Ausführung Bewusstsein und Mut zu Veränderung oder fühlen sich die Mitarbeiter gar zur Ideenfindung gezwungen? Im Folgenden werden die Genese und Kontexteinbettung der einzelnen Instrumente des Innovationssystems detaillierter ausgeführt. So wurde versucht herauszuschälen, wie sich allmählich unerwartete Nebenfolgen einstellen, sich Praktiken sogar von ihren originären Zwecken zu lösen beginnen, aber auch, wie vermeintlich ungebundene Arrangements miteinander wechselwirken. Vor allem soll aufgezeigt werden, dass sich die Bewertung der Viabilität äußerst diffizil gestaltet - der Forscher häufig gezwungen wird, Ambiguität aufzulösen, die sich in diesem Ausmaß wohl in quantitativen Untersuchungen nicht zu erkennen gegeben hätte. Die Ausführung der empirischen Ergebnisse mündet schließlich in eine Beschreibung der reflexiven und institutionellen Ausprägungen der Instrumente (in tabellarischer Form) bzw. deren „verschränktem“ Zusammenhang. Damit soll herausgearbeitet werden, inwiefern die Viabilität eines solchen Arrangements nur mit Bezug zu beiden Attributen angemessen beurteilt werden kann.

\subsubsection{Innovationsmanagement in persona}

Ursprünglich war das Innovationsmanagement organisationsstrukturell Teil der F\&E. Die starke mediale Präsenz der Sportiva, der damit einhergehende hohe Bekanntheitsgrad und die sich zunehmend vereinfachende digitale Kommunikation führten schon vor einigen Jahren zu einer Überhäufung mit technischen Verbesserungsvorschlägen und Ideen externer Erfinder und Tüftler. Um die zugesandten Ideen angemessen auf ihr Potenzial überprüfen zu können und ggf. in den Produktentstehungsprozess einfließen zu lassen, wurde die funktionale Stelle des Innovationsmanagers geschaffen. Einige Zeit nachdem sich die Einheit erfolgreich etablierte, versuchte die Sportiva (unterstützt durch externe Berater), wie bereits erwähnt, ihr eigenes Modernisierungsverständnis, weg von der herkömmlichen 
„Herstellungs-, Material- bzw. Produktgetriebenheit“, hin zu mehr „Nutzerorientierung“ zu wandeln, letztlich eine „consumer- $\&$ brand-led organization“ zu werden. In einem der ersten Schritte trennte sie dazu das Innovationsmanagement organisatorisch von der F\&E und baute es personell aus. Damit sollte seine Zuständigkeit auf die anderen Geschäftsbereiche ausgedehnt und gleichzeitig nicht-technische Innovationen gefördert werden. Die Sportiva folgte damit einer Managementströmung, die zu jener Zeit besonders um sich zu greifen schien. ${ }^{14}$

Aus der Not gewachsen, existierte für den Innovationsmanager kein konkretes Tätigkeitsprofil, mithin ein heterogenes Verständnis seiner eigentlichen Funktion. Er sah sich fortan mit verschiedenen Rollenerwartungen konfrontiert. Einerseits wurde er mit dem Management konkreter Innovationsprojekte betraut, welche gerade in der frühen Produktentwicklung oft unerwartet viel Kapazität binden. Andererseits erwarteten Mitarbeiter, dass sie bei der Generierung von Ideen methodisch unterstützt werden und ihm deshalb vielmehr die Funktion eines „Enablers“, „Impulsgebers“ und „Inspirators“ zukäme, der primär ein ermöglichendes Umfeld schafft, in dem Mitarbeiter kreativ werden können. Überdies trat er selbst des Öfteren als Ideengeber auf, was in Summe schließlich zu Rollenkonflikten und Kapazitätsengpässen führte.

Eine ähnliche Ambivalenz tritt bei der Bewertung des Innovationsmanagements durch die Mitarbeiter und Führungskräfte zutage..$^{15}$ Denn entgegen der programmatischen Maßnahmen und des Engagements, beschreiben einige Stimmen die Aktivitäten zur Ideengenerierung als „leblos" oder „brachliegend“:

„Also, wenn ich jetzt 'ne Pressekonferenz geben würde, dann würde ich ihnen natürlich jetzt hier sagen, wie toll das alles hier funktioniert. Die Wahrheit ist die, dass eigentlich die Prozesse, die wir da haben und das Set-up in meinen Augen eher unbefriedigend sind." (Senior Manager, Interview)

„Dieser Karren steckt im Dreck und er muss reaktiviert werden. “ ... „Insgesamt fehlt mir ein System (...) wo wir konsequent und kontinuierlich Ideen generieren, die evaluieren und die besten davon weitertreiben. Das ist eingeschlafen bei uns." (Senior Manager, Interview)

Ergänzend zu diesen Einschätzungen soll ein Blick auf den Füllstand des Ideenspeichers der Sportiva vor allzu verzerrenden Momentaufnahmen einzelner Mitarbeiter schützen. Doch brächte die bloße Anzahl gelisteter Ideen kaum Mehrwert: Wer vermag schon, ihr zukünftiges Potenzial beurteilen zu können. Viel aufschlussreicher sind die Interpretationen und Bewertungen der Situation durch die Mitarbeiter:

„Wir haben genug Ideen, wir müssen jetzt mal schauen, dass wir die Ideen aufs Papier bringen und jetzt nicht irgend so einen Trichter füllen. " (Manager zitiert Senior Manager, Interview)

„Witzigerweise hab' ich jetzt ein totales Loch auf der frühen Innovationsphase. Also ich weiß momentan nicht, was die nächsten Projekte sind, die in vier Jahren ein Produkt

14 Siehe auch Fader (2012), einer der Vorreiter der „Customer Centricity“-Bewegung.

15 Bereits 2011 ließ eine Studie zu den Innovationsaktivitäten, die von externen Beratern durchgeführt wurde, eine gewisse Unzufriedenheit erkennen. 
werden sollen." ... „Wir haben jetzt nichts mehr im Bauchladen, was man rausnehmen kann." (Senior Manager, Interview)

Auch hier lässt sich also kein homogenes Bild konstruieren. Im Gegenteil: Widersprüchlicher könnten die Aussagen kaum sein. Hier scheint also etwas nicht zu stimmen. Die ambivalente Bewertung speist sich vermutlich nicht unwesentlich aus dem internen Wettbewerb mit der projektförmig organisierten Initiative aus Abs. 4.2.5, mit der implizit auch die Zustimmung des Top-Managements schwindet. Die hochgradig ausgeprägte Reflexivitätsdimension führt aufgrund ihrer entkräftenden Institutionalisierung (Rollenkonflikte, Personifizierung, ungenügende disziplinarische Befugnisse, etc.) nicht (zumindest nicht einstimmig) zu den gewünschten Effekten.

\begin{tabular}{|c|c|c|c|}
\hline & Kriterium & Ausprägung im Untersuchungsobjekt & \\
\hline \multirow{5}{*}{ 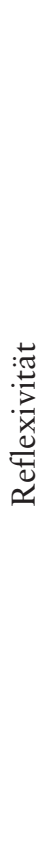 } & $\begin{array}{l}\text { Kanäle/Grad } \\
\text { für Rückkopp- } \\
\text { lungen }\end{array}$ & $\begin{array}{l}\text { Selbstverständlicher und regelmäßiger Einsatz externer Berater und } \\
\text { Forscher zur Revision und Potenzialanalyse sämtlicher Innovations- } \\
\text { aktivitäten und -einrichtungen. Periodische Auswertung repräsentati- } \\
\text { ver Marktumfragen, um die Wirksamkeit des Innovationsmanage- } \\
\text { ments u.a. über den Produkterfolg und die Markenwahrnehmung zu } \\
\text { spiegeln. }\end{array}$ & O \\
\hline & $\begin{array}{l}\text { Fernwirkun- } \\
\text { gen }\end{array}$ & $\begin{array}{l}\text { Verarbeitung von Innovationsideen interner Mitarbeiter aller Abtei- } \\
\text { lungen, dem erweiterten Firmennetzwerk sowie externer Ideengeber } \\
\text { gleichermaßen. }\end{array}$ & (1) \\
\hline & $\begin{array}{l}\text { Kriterien- und } \\
\text { Zielrevision }\end{array}$ & $\begin{array}{l}\text { Regelmäßige Gate-Meetings und Innovationstage bieten Plattform für } \\
\text { Dialog und Neuausrichtung zukünftiger Produktinnovationsbemü- } \\
\text { hungen. }\end{array}$ & ( \\
\hline & $\begin{array}{l}\text { Grad der An- } \\
\text { wendung/ } \\
\text { Aussetzung }\end{array}$ & $\begin{array}{l}\text { Etabliertes Innovationsmanagement steht in Konkurrenz zum „Future } \\
\text { Product“-Projekt (Abs. 4.2.5) bzw. wird von diesem sogar ausgehe- } \\
\text { belt (interner Wettbewerb). Dieser Wettbewerb setzt beteiligte Mitar- } \\
\text { beiter spürbar unter Druck (u.a. aufgrund widersprüchlicher Arbeits- } \\
\text { anforderungen). }\end{array}$ & (1) \\
\hline & $\begin{array}{l}\text { Selbstanwen- } \\
\text { dung }\end{array}$ & $\begin{array}{l}\text { Teilnahme an branchenübergreifenden Innovationsnetzwerken sensi- } \\
\text { bilisiert für Möglichkeiten alternativer Ausgestaltung und verstetigt } \\
\text { Dialog über ähnliche Problemstellungen/Lösungen in anderen Firmen. } \\
\text { Innovationsmanagement stellt sich damit selbst auf den Prüfstand. }\end{array}$ & (1) \\
\hline
\end{tabular}




\begin{tabular}{|c|c|c|c|}
\hline & Kriterium & Ausprägung im Untersuchungsobjekt & \\
\hline \multirow{7}{*}{ 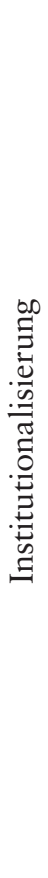 } & \multirow[t]{2}{*}{ Legitimität } & $\begin{array}{l}\text { Etablierte organisationale Einheit, aufbaustrukturell neutral verortet. } \\
\text { Erfahrener und von Kollegen geschätzter Innovationsmanager. }\end{array}$ & ( \\
\hline & & $\begin{array}{l}\text { Aufgrund sprungfixer Hierarchie der ständigen Gefahr ausgesetzt, } \\
\text { plötzlich entkräftet zu werden. }\end{array}$ & (1) \\
\hline & Formalität & $\begin{array}{l}\text { Fehlende Rollenbeschreibung des Innovationsmanagers führt zu wi- } \\
\text { dersprüchlichen Arbeitsanforderungen und zu irritierten Erwartungs- } \\
\text { haltungen bzgl. der Verantwortung, neue Ideen hervorzubringen, was } \\
\text { wiederum zu latenten Grabenkämpfen zwischen Innovationsmanager } \\
\text { und F\&E-Abteilungen führt. }\end{array}$ & (1) \\
\hline & Faktizität & $\begin{array}{l}\text { Zuschreibung von Erfolg und Misserfolg nachhaltig an Protagonisten } \\
\text { gekoppelt: Das Innovationsmanagement „steht und fällt“ mit dem In- } \\
\text { novationsmanager. }\end{array}$ & (1) \\
\hline & \multirow[t]{2}{*}{ Signifikanz } & $\begin{array}{l}\text { Vor dem Hintergrund innovativer Wettbewerber und kurzer Innovati- } \\
\text { onszyklen wird die Notwendigkeit regelgeleiteter gesamtorganisatio- } \\
\text { naler Innovationsförderung durchaus wahrgenommen. }\end{array}$ & (1) \\
\hline & & $\begin{array}{l}\text { Funktions- und abteilungsübergreifende personelle Besetzung der Rol- } \\
\text { le schafft Perspektivenvielfalt und verringert wahrgenommene Dis- } \\
\text { tanz (konkurrierendes Abteilungsdenken). }\end{array}$ & (1) \\
\hline & $\begin{array}{l}\text { Durchset- } \\
\text { zungsmecha- } \\
\text { nismen }\end{array}$ & $\begin{array}{l}\text { Fehlende disziplinarische Befugnisse des Innovationsmanagers ermög- } \\
\text { lichen den Abteilungen Innovationsaktivitäten in Eigenregie. }\end{array}$ & (1) \\
\hline
\end{tabular}

Tabelle 3: Reflexivität und ihre Institutionalisierung: „Innovationsmanagement in persona"

Vermutlich nicht zuletzt, um dem Management auf Wunsch einen Effizienznachweis liefern zu können, wurde eine dedizierte Innovations- und Ideenmanagementsoftware eingeführt, welche die Innovationsaktivitäten der Sportiva zwar weiter systematisierte, aber auch nicht frei von Nebenfolgen Anwendung fand, wie sich im Folgenden zeigen wird.

\subsection{2 „NeXt“ - Innovations- und Ideenmanagementsoftware}

Der ursprüngliche Grund für die Einführung einer Ideen- bzw. Innovationsmanagementsoftware war die stetige Zunahme neuer Produktideen. Der Einsatz selbstgestrickter Behelfslösungen verlor mit steigender Anzahl neuer Ideen immer mehr an Attraktivität, weshalb schließlich auf eine professionelle Lösung zurückgegriffen wurde: „NeXt“ ${ }^{16}$ Es sollte damit vordergründig eine orts- und personenunabhängige Datenbank samt digitalisiertem Workflow etabliert werden, der die Mitarbeiter bei der Entstehung und Weiterentwicklung neuer Ideen unterstützt und damit die formlos zugeschobenen Schmierzettel und Skizzen ersetzen sollte. Laut Angaben des Herstellers der Software, für die sich die Sportiva letztlich entschied, fördere der Einsatz außerdem „mehr Transparenz“ und „anhaltendes Engagement“ im Innovationsprozess, wie auch die Identifikation „leidenschaftlicher Unterstützer" der Ideen. Zwar konnte der angestrebte Zweck, Ideen systematischer zu verwalten, durch das Softwaresystem letztlich ohne weitere Anstrengungen erfüllt werden, doch fand

16 Kunstwort zur Wahrung der Anonymität des untersuchten Unternehmens. 
NeXt bei den Mitarbeitern, entgegen jeder Absicht, allmählich immer weniger Akzeptanz und infolgedessen immer weniger Anwendung. Die Datenbank wurde aus Sicht einiger Mitarbeiter sogar als „Ideenfriedhof“ bezeichnet. Doch wodurch entstand diese plötzliche Ablehnung? Nun, diese Entwicklung lässt sich wohl genauso wenig monokausalistisch erklären wie alle anderen Erkenntnisse aus dieser Untersuchung. Es ist vielmehr eine Verkettung ungewollter Nebenfolgen, die es herauszuarbeiten gilt.

Es darf vermutet werden, dass diese unbeabsichtigte Wendung nicht allein auf den Einsatz von NeXt zurückzuführen ist, da sich die Datenbank unmittelbar nach ihrer Einführung zunächst äußerst rasch mit Einträgen füllte. Das war auch so gewollt und notwendig. Denn ein wesentlicher Bestandteil des Innovationssystems der Sportiva (der noch ausführlicher behandelt wird) ist ein Prozess namens „Stage-Gate“, der die Mitarbeiter von der Ideengenerierung bis zur konkreten Entwicklung begleitet, dabei jedoch in der ersten Phase auf möglichst viele Ideen angewiesen ist, um seine eigentliche Funktion erfüllen zu können. Und diese Funktion erfüllt er umso besser, je höher die Anzahl der Ideen und je geringer ihr Detaillierungsgrad ist, dazu jedoch später mehr. Aus dieser Notwendigkeit entstand schließlich eine Handlungsmaxime, die das Ideentum der Sportiva maßgeblich beeinflusste und zur Erklärung dieser unbeabsichtigten Entwicklung beiträgt: „Quantität vor Qualität“. Die quantitative Forderung nach neuen Ideen schlug sich sogar in den Zielvereinbarungen einiger Mitarbeiter nieder und wurde per Dekret eingefordert:

„Uns wurde immer so gesagt: ,Quantität, Quantität, Ideen eintragen, Ideen eintragen“. “ (Manager, Interview)

Doch resultierte ein häufiges Argument für die Ablehnung von NeXt gerade erst aus einer ungewollten Wirkung, die durch die Forderung nach mehr Ideen entstand:

„Hauptsache du gibst was ein, ins System, aber es ist halt nur Schrott.“ (Manager, Interview)

„Da sind 1000 Ideen und wirklich die Hälfte davon würde ich löschen, löschen, löschen." (Manager, Interview)

Es war nach Aussagen einiger Mitarbeiter zwischenzeitlich nicht nur die schiere Anzahl der Ideen, die demotivierend wirkte, sondern vor allem auch die Tatsache, dass der Quantität Vorrang eingeräumt wurde. Denn zum einen hatte dies zur Folge, dass die Wertigkeit und damit das Interesse an der Datenbank, gemessen am intellektuellen Kapital, das in ihr gespeichert ist, mehr und mehr versiegten. ${ }^{17}$ Und zum anderen könnte sich hier die Ursache verstecken, weshalb es den Mitarbeitern indes so schwerfällt, kreativ zu sein:

„Also die neue Generierung von Ideen (...) funktioniert nur noch ganz ganz zaghaft und zäh. Vielleicht auch schon, weil so viele Ideen in der Datenbank drin sind." (Manager, Interview)

Im Übrigen hatte diese Direktive zur Konsequenz, dass sich die bloße Anzahl neuer Ideen sogar als inoffizieller Leistungsmaßstab etablierte. Denn Quantität lässt sich nicht nur präzise messen und damit bewerten, sondern auch vergleichen (während die qualitative Dimension dabei jedoch kaum Beachtung fand). Nun konnten neben ganzen Organisationseinheiten auch einzelne Mitarbeiter anhand der Menge ihrer Datenbankeinträge miteinan-

17 Außerdem begünstigt die Urheberschaft einer Idee und die damit verbundene Anerkennung die Entfaltung intrinsischer Motivation - zumindest solange die Ideen nicht im Überangebot untergehen. 
der verglichen werden. Und so führte schließlich auch die Transparenz über die Herkunft und Anzahl der Ideen - mit welcher der Hersteller von NeXt sogar warb - bei einigen Mitarbeitern zu Unbehagen. Das darf vermutet werden, gerade weil ungefragt so häufig der Vorzug qualitativer Güte neuer Ideen bekräftigt wurde:

„Mit Quantität kann man relativ wenig anfangen. Ideen sollten halt qualitativ gut sein und von qualitativ wirklich guten Ideen gibt es halt nicht so viele (...) Also auf Kommando gute Ideen produzieren, das ist schwierig. " (Manager, Interview)

Um die wachsende Datenmenge effizient verarbeiten und die Suchfunktionen überhaupt nutzen zu können, war es außerdem notwendig, neue Einträge formalisiert mittels Eingabemasken und Pflichtfeldern zu vereinheitlichen. Das schränkt nicht nur Vielfalt ein, sondern zeichnet Ideen gewissermaßen vor - in einem Unternehmen mit technikdominantem Modernisierungsverständnis folglich zugunsten technischer Aspekte (Zeichnungen, Pläne, ...). Außerhalb der F\&E wird NeXt vermutlich deshalb als „zu technisch“ in seiner Ausführung beschrieben, was Mitarbeiter zusätzlich abschreckt. Auf die Frage, weshalb denn $\mathrm{NeXt}$ indes so wenig Akzeptanz erfährt, erwiderten einige, es herrsche eine andere Kultur vor, eher eine Kultur des dialogischen Austauschs, Kreativität entstünde eher „am Kaffeeautomat“, ungeplant und ungezwungen, als wenn jeder „den ganzen Tag an seinem Computer" sitzt. Durch NeXt aber wird die Innovationskultur erst greifbar - und damit erst diskutabel. Denn gerade durch ihre strukturierende und systematisierende Wirkung wirft sie Fragen auf, die bislang keiner stellte. Mit ihr wird plötzlich ein Ort festgelegt, an dem Ideen explizit werden, eine Form abgesteckt, in die Ideen passen sollen, aber auch eine entpersonifizierte Erwartungshaltung institutionalisiert, die Zwang ausübt, Ideen zu generieren. Offensichtlich erzeugt sie vielmehr ein unbehagliches Gefühl, als sie als Chance zur Findung einer adäquaten Innovationskultur verstanden wird.

\begin{tabular}{|c|c|c|c|}
\hline & Kriterium & Ausprägung im Untersuchungsobjekt & \\
\hline \multirow{5}{*}{ 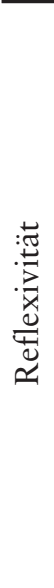 } & $\begin{array}{l}\text { Kanäle/ Grad } \\
\text { für Rückkopp- } \\
\text { lungen }\end{array}$ & $\begin{array}{l}\text { Ergebnisbeurteilung in Gate-Meetings (Abs. 4.2.4) vorgesehen, je- } \\
\text { doch mitunter verzerrt durch wechselhafte Atmosphäre, häufig vari- } \\
\text { ierende Zusammensetzung der Teilnehmer und Zeitdruck. }\end{array}$ & 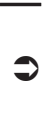 \\
\hline & Fernwirkungen & $\begin{array}{l}\text { Grundsätzlicher Einbezug aller Mitarbeiter, Nutzungsintensität je- } \\
\text { doch (nur mittelbar) von individualpsychologischer Motivation zur } \\
\text { Ideengenerierung abhängig. }\end{array}$ & $\vartheta$ \\
\hline & $\begin{array}{l}\text { Kriterien- und } \\
\text { Zielrevision }\end{array}$ & $\begin{array}{l}\text { Möglichkeit zur Revision ist nicht vorgesehen. Beurteilung der Wirk- } \\
\text { samkeit des Verfahrens über Anzahl der Ideen etabliert (quantitativ), } \\
\text { nicht aber über deren Potenzial. }\end{array}$ & (1) \\
\hline & $\begin{array}{l}\text { Grad der An- } \\
\text { wendung/ Aus- } \\
\text { setzung }\end{array}$ & $\begin{array}{l}\text { Aussetzung durch oberes Management teilweise geduldet (sogar ver- } \\
\text { ordnet), was Aufwand-Nutzen-Verhältnis und Sinnhaftigkeit bei den } \\
\text { Mitarbeitern fortlaufend und zunehmend infrage stellt. }\end{array}$ & (1) \\
\hline & $\begin{array}{l}\text { Selbstanwen- } \\
\text { dung }\end{array}$ & Kein Kanal für Kritik oder Feedback am Verfahren vorgesehen. & (1) \\
\hline
\end{tabular}




\begin{tabular}{|c|c|c|c|}
\hline & Kriterium & Ausprägung im Untersuchungsobjekt & \\
\hline \multirow{5}{*}{ 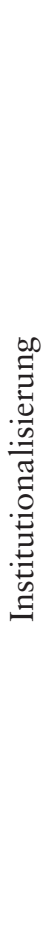 } & Legitimität & $\begin{array}{l}\text { Mitschwingende Quantitätsmaxime ,je mehr, desto besser“ und öf- } \\
\text { fentliche Einsicht aller Einträge schafft Vergleichbarkeit, Kontroll- } \\
\text { möglichkeit und inoffiziellen Leistungsmaßstab, wodurch Druckemp- } \\
\text { finden bei Mitarbeitern erzeugt und infolgedessen Akzeptanz verrin- } \\
\text { gert wird. }\end{array}$ & (1) \\
\hline & Formalität & $\begin{array}{l}\text { Formulargestalt und vereinheitlichter Workflow fördert systemati- } \\
\text { sches Vorgehen und Findung einer Innovationskultur, aber schränkt } \\
\text { die Vielfalt und Einzigartigkeit in der Ideenentwicklung und -explika- } \\
\text { tionsweise gleichzeitig ein. }\end{array}$ & $\partial$ \\
\hline & Faktizität & $\begin{array}{l}\text { Digitalisierter Workflow fördert Reichweite des Tools (durch } \mathrm{Zu} \text { - } \\
\text { gang/ Werbung via Intranet) und verringert örtliche und zeitliche Bar- } \\
\text { rieren bei der Ideeneinreichung. Softwaregestalt und Reputation des } \\
\text { externen Herstellers entpersonalisiert den Zweck und schützt den fir- } \\
\text { meninternen Initiator vor Schuldzuschreibung. }\end{array}$ & (1) \\
\hline & Signifikanz & $\begin{array}{l}\text { Verwaltungsfunktion als ursprünglicher Grund der Einführung wich } \\
\text { zum Teil der Repräsentationsmöglichkeit und Erfolgsmessung des In- } \\
\text { novationsmanagements. } \\
\text { Schiere Anzahl eingetragener Ideen verringert den wahrgenommenen } \\
\text { Bedarf an neuen Ideen und führt zu einer Vernachlässigung qualitati- } \\
\text { ver Gütekriterien. }\end{array}$ & (1) \\
\hline & $\begin{array}{l}\text { Durchsetzungs- } \\
\text { mechanismen }\end{array}$ & $\begin{array}{l}\text { Anzahl eingebrachter Ideen wirken sich über Zielvereinbarungen auf } \\
\text { individuelle Löhne aus. Das fördert Eigennutzmaximierungsstrategi- } \\
\text { en und damit Kluft zwischen System- und Partialinteresse („Hidden } \\
\text { Agenda“). }\end{array}$ & (1) \\
\hline
\end{tabular}

Tabelle 4: Reflexivität und ihre Institutionalisierung: „NeXt“

Der eigentliche Zweck, weshalb NeXt eingesetzt wurde, konnte problemlos erfüllt werden. Erst durch die systemische „Brille“ wurde sichtbar, dass die unerwarteten Nebenfolgen ihre Ursachen nicht selten in den Interaktionseffekten mit anderen Instrumenten des Innovationssystems finden. Während die idealtypisch vorgezeichnete Anwendung des Softwaresystems (für sich genommen) keine nachteiligen Konsequenzen erwarten ließ, stellte sich schließlich weder genügend Akzeptanz unter den Nutzern ein, noch führten in Aussicht gestellte Boni zu mehr verwertbaren Ideen. Selbst in der Reflexivitätsdimension bietet das Instrument wenig Spielraum für Weiterentwicklungen bzw. Anpassungen. Doch begeben wir uns zurück auf die Ebene der operativen Begründungspflicht, nämlich neue Ideen nach formalen Kriterien systematisch zu erfassen, um sie im Stage-Gate-Prozess von einem ausgewählten Gremium filtern und schließlich vom Projektteam weiterverfolgen zu lassen, sofern ihnen Potenzial attestiert wurde. Die Generierung dieser neuen Ideen wurde dabei von zahlreichen Veranstaltungen in unterschiedlichsten Formaten flankiert.

\subsubsection{Innovationstage, Kick-Off-Meetings und Brainstormings}

Das Innovationsmanagement des Unternehmens organisierte regelmäßig Events in unterschiedlichen Zyklen mit dem Ziel, neue Ideen zu kreieren, wie auch bestehende Sichtweisen und Zustände im Unternehmen infrage zu stellen. Dreimal im Jahr fanden die sogenannten „Innovationstage“ statt. Für etwa 50 Mitarbeiter aus unterschiedlichen Funkti- 
onsbereichen und Hierarchieebenen (bewusst interdisziplinär zusammengestellt) wurden dazu ein- bis zweitägige Workshops organisiert. Nach dem Besuch eines Impulsgebers (u.a. Erfinder, Experten oder Unternehmen) wurde anschließend in möglichst angenehmer Atmosphäre versucht, kreativ an neuen Ideen zu arbeiten, so der Ablaufplan. Doch ließ sich bei der Bewertung des Outputs durch die Teilnehmer auch hier kein einheitliches Bild nachzeichnen - einige Teilnehmer beurteilten die Ergebnisse positiv, andere negativ. Das mag zwar auf unterschiedliche Wissensstände, u.a. was die Neuheit eingebrachter Ideen betrifft, wie auch auf differierende Erwartungshaltungen zurückzuführen sein. Mit der mehr oder weniger verpflichtenden Teilnahme bzw. dem herkömmlichen Arbeitstag als weniger reizvolle Alternative, wurden aber auch Opponenten eingeladen. Was außerdem durchweg bemängelt wurde, war, dass jegliche Ergebnisse folgenlos blieben.

„Man ist am nächsten Tag in die Firma gegangen und dann war es so, als wäre der Tag nie gewesen. Man hat nie mehr was davon gehört, was da irgendwie so gebrainstormt wurde. Es wurde nix nachverfolgt. Es wurde nie was erzählt." (Manager, Interview)

Das kann verschiedene Gründe haben. Einer davon ist sicherlich eine unzureichende Informationspolitik - selbst wenn Ideen durch die F\&E weiterverfolgt wurden, fehlte womöglich lediglich das Feedback an die Teilnehmer. Unterdessen sahen die Teilnehmer auch nicht mehr den eigentlichen Zweck (die Ideenfindung) im Vordergrund, sondern verstanden (und nutzten) das Event schließlich als gesellige und teambildende Maßnahme. Außerdem wurde (erneut) das Format bemängelt, also die Art und Weise, wie den Ideen zu ihrer Entstehung verholfen werden soll.

„Ich mein, wie sollen mir geplant einfach die Ideen kommen." (Senior Manager, Interview)

Diese Auffassung zeigt, dass die Innovationstage weniger als ungezwungene Hilfestellung zur Förderung neuer Ideen und Konzepte, denn vielmehr als ein Plan verstanden wurden, der sich ja immer nur in Verbindung mit einem Ziel denken lässt. Obgleich dieses hier lediglich als Möglichkeit zur Inspiration und Anregung kollektiver Interaktionseffekte gefasst wurde, scheint eine unterdrucksetzende Erwartungshaltung mitzuschwingen. Auch hier lassen sich Ausprägungen unternehmenskultureller Motivationsquellen erkennen, die sich auf soziale Anerkennung aus kreativer Leistung zurückführen lassen. Doch fanden die Innovationstage in den letzten zwei Jahren nicht mehr statt - ein bedingungsloser Bestandserhalt trotz attestierter Fruchtlosigkeit wäre schließlich auch nicht erstrebenswert. Das Problembewusstsein hatte sogar eine Analyse der Innovationsaktivitäten durch externe Berater zur Folge.

Neben den Innovationstagen fand einmal im Jahr ein sog. „Kick-Off-Meeting “ statt. Auch dort bekamen Mitarbeiter die Möglichkeit, ausgewählte Themen, z.B. Führungskultur, Markenbildung oder Ideen zu neuen Produkten in Gruppen zu bearbeiten, d.h. ihr Verständnis zu explizieren und Veränderungswünsche zu kommunizieren. Doch auch dieser Versuch der Mitarbeiterpartizipation wurde mehrheitlich der Folgenlosigkeit beschuldigt.

Des Weiteren fanden wöchentlich einstündig sog. „Freitags-Brainstormings“ statt, bei welchen fünf bis sieben Mitarbeiter, hauptsächlich aus der F\&E - aber „prinzipiell offen“ für alle - zu vorgeschlagenen oder auch selbst eingebrachten Themen kreativ werden sollten. Obwohl die Atmosphäre als „frei“ empfunden wurde, in der auch mal „gesponnen“ werden durfte und selbst die Ergebnisse für gut befunden wurden, stellten sie auch dieses 
Format alsbald ein. Am nötigen Durchhaltevermögen mangelte es vermutlich nicht zuletzt aufgrund der eher informellen, weichen Institutionalisierung. Bisweilen findet nur noch innerhalb der F\&E ein Austausch über neue Ansätze statt. Diese Entwicklung kann auch als Abkehr von der einst bewusst mobilisierten Bewegung zu mehr Kundenorientierung und einem gesamtheitlicheren, interdisziplinären Innovationsverständnis begriffen werden, das einst sogar mit Unterstützung externer Berater eingeführt wurde.

\begin{tabular}{|c|c|c|c|}
\hline & Kriterium & Ausprägung im Untersuchungsobjekt & \\
\hline \multirow{5}{*}{ 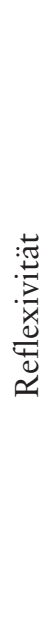 } & $\begin{array}{l}\text { Kanäle/ Grad } \\
\text { für Rückkopp- } \\
\text { lungen }\end{array}$ & $\begin{array}{l}\text { Ausflugsziel der Innovationstage sind externe Referenten, um Impul- } \\
\text { se zu liefern und Kreativität unter den Mitarbeitern zu fördern. }\end{array}$ & 0 \\
\hline & Fernwirkungen & $\begin{array}{l}\text { Je nach Veranstaltung wird nur ein auserwählter Teilnehmerkreis } \\
\text { einbezogen. Dessen Auswahl erfolgte dabei nicht nach dem Kriteri- } \\
\text { um der Motivation oder Kreativität. }\end{array}$ & (1) \\
\hline & $\begin{array}{l}\text { Kriterien- und } \\
\text { Zielrevision }\end{array}$ & $\begin{array}{l}\text { Themen der Veranstaltungen sind vorgegeben, aber sollen sich an ge- } \\
\text { gebenen Anlässen ausrichten. Die Themenwahl wurde jedoch alles in } \\
\text { allem wohlwollend beurteilt. }\end{array}$ & $\vartheta$ \\
\hline & $\begin{array}{l}\text { Grad der An- } \\
\text { wendung/ Aus- } \\
\text { setzung }\end{array}$ & $\begin{array}{l}\text { Events dienen lediglich der Findung von Verbesserungspotenzialen. } \\
\text { Aufarbeitung der Ergebnisse (im Kollektiv) bzw. tatsächliche Umset- } \\
\text { zung ist nicht Teil des Verfahrens. }\end{array}$ & (1) \\
\hline & $\begin{array}{l}\text { Selbstanwen- } \\
\text { dung }\end{array}$ & $\begin{array}{l}\text { Beständigkeit trotz andauernder Kritik begründet sich vermutlich mit } \\
\text { dem Fehlen adäquater Alternativen und dem positiven Nebeneffekt } \\
\text { eines behaglichen Teamevents. }\end{array}$ & (1) \\
\hline \multirow{7}{*}{ 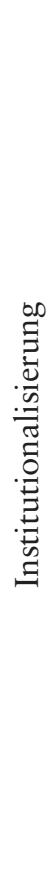 } & Legitimität & $\begin{array}{l}\text { Implizite Erwartungshaltung, zahlreiche neue Ideen zu generieren, } \\
\text { wie auch die fehlende Mitbestimmung bei der Themenwahl, führte } \\
\text { zu Verdruss und Ablehnung unter den Mitarbeitern. }\end{array}$ & (1) \\
\hline & Formalität & $\begin{array}{l}\text { Systematisches Vorgehen endete mit der Veranstaltung selbst. Die } \\
\text { Verwertung der Resultate bleibt dem Zufall überlassen (was auch ein } \\
\text { wesentlicher Grund für die fehlende Legitimität sein kann). }\end{array}$ & (1) \\
\hline & & $\begin{array}{l}\text { Grad der Formalität erstreckt sich von hoch (Innovationstage und } \\
\text { Kick-Off-Meetings) bis niedrig (Freitags-Brainstormings). }\end{array}$ & 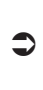 \\
\hline & Faktizität & $\begin{array}{l}\text { Alle drei Formate blicken auf eine nunmehr langjährige Tradition zu- } \\
\text { rück. Mitunter deshalb wurde es zwar in den letzten Jahren nicht } \\
\text { mehr durchgeführt, aber dennoch nicht offiziell aufgekündigt bzw. } \\
\text { durch Alternativen substituiert. }\end{array}$ & 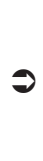 \\
\hline & Signifikanz & $\begin{array}{l}\text { Aufgrund ausbleibender bzw. schlecht kommunizierter Erfolge wich } \\
\text { der Zweck, neue Ideen zu generieren, der unterhaltsamen Funktion } \\
\text { eines Teamevents. }\end{array}$ & () \\
\hline & $\begin{array}{l}\text { Durchsetzungs- } \\
\text { mechanismen }\end{array}$ & $\begin{array}{l}\text { Teilnahme an den Innovationstagen und den Kick-Off-Meetings wird } \\
\text { weniger formell vorgeschrieben (auch begünstigt durch „nicht ex- } \\
\text { trem sklavische“ Unternehmenskultur), denn informell eingefordert. }\end{array}$ & $\vartheta$ \\
\hline & & $\begin{array}{l}\text { Mechanismen zur Durchsetzung der „Freitags-Brainstormings“ rein } \\
\text { informell: Der hohe Selbstanspruch (High-Performance Brand) för- } \\
\text { dert den freiwilligen Dialog. }\end{array}$ & O \\
\hline
\end{tabular}

Tabelle 5: Reflexivität und ihre Institutionalisierung: „Innovationsevents“ 
Selbst bei einem solch mitarbeiterfreundlichen Format verpufft jegliches Engagement (und damit auch Aussicht auf Resultate), wenn aus den Bemühungen der Teilnehmer keine Konsequenzen zu erwarten sind. Betrieb die Sportiva vielleicht sogar zu viel „Ideation“? $\mathrm{Zu}$ viel in zu kurzer Zeit? Zu viel im Verhältnis zum Potenzial, das die Branche bzw. der Markt bietet? Um jedenfalls das Vorgehen nach der Entstehung einer erfolgversprechenden Idee zu systematisieren, etablierte die Sportiva einen Prozess. Es ist ein folgenreicher Baustein des institutionalisierten Innovationssystems der Sportiva.

\subsubsection{Stage-Gate-Prozess ${ }^{\circledR}$ - „Von der Idee bis zur Markteinführung“}

Bereits vor mehr als zehn Jahren wurde bei der Sportiva ein sog. „Idea-to-Launch-Prozess“ eingeführt. Er zeichnet den Weg von einer neuen Idee bis zu ihrer Markteinführung operativ vor und soll damit Effektivität und Effizienz erhöhen, so Cooper (vgl. 2008, 214 ff.), der den Stage-Gate-Prozess in den 1980ern konzipierte, in einer aktuelleren Veröffentlichung. Dieser Entwicklungsprozess für Neuprodukte besteht in seiner einfachsten Form aus fünf Phasen („Stages“), die sich jeweils gekoppelt durch ein Tor („Gate“) aneinanderreihen. In jeder dieser Stages ist das Projektteam aufgefordert, ein standardisiertes Set an Informationen zu beschaffen und bestimmte Aktivitäten auszuführen („Deliverables“). Damit soll sichergestellt werden, dass Unbekanntes und Unsicherheiten in angemessenem Verhältnis zu den steigenden Entwicklungskosten abnehmen und damit Risiken für das Unternehmen sukzessive reduziert werden. In „Gate Meetings“ werden die Projektstadien sämtlicher Ideen dann regelmäßig einem ausgewählten, i.d.R. interdisziplinären, hierarchie-übergreifenden Gremium vorgestellt, das anhand der Erfüllung vordefinierter „MustMeet-Criteria" schließlich entscheidet, ob das anvisierte Gate vom Projektteam passiert werden darf, die Idee (vorerst) nicht weiter verfolgt werden soll oder ob Nachbesserungen notwendig sind („Go/ Kill/ Hold/ Recycle“). Mit Cooper ist es kein bürokratisches „Regelbuch“, das einen linearen, sequentiellen Prozess beschreibt, der als „Projekt-Kontrollmechanismus“ genutzt werden soll, denn eher ein „playbook designed to enable project teams and team leaders get resources for their projects and then to speed them to market using the best possible methods to ensure success" (Cooper 2008, 216). Der Stage-GateProzess soll Unternehmen eine Art „Landkarte“ zur Verfügung stellen, auf der sie, trotz der Unmöglichkeit, Neues zu planen, letztlich nicht die Orientierung verlieren, dabei aber weder Projekt-, noch Portfoliomanagement ersetzen. Doch, und damit sei die Beschreibung abgerundet, entfaltet sich das Konzept erst vor dem Hintergrund eines Trichters, dessen Zweck es ist, aus zunächst vielen Ideen mittels Prüfintervallen (Gates) allmählich solche herauszufiltern („Funneling effect“), die sich als nur mäßig entpuppen (vgl. Cooper 2008, 220). Dieses Prinzip kann seinen erwarteten Effekt also umso besser entfalten, je mehr Ideen zu Beginn in den Trichter „gekippt“ werden. Doch warum wurde dieser Prozess überhaupt bei der Sportiva eingeführt?

Nun, unstrittig ist, dass der bereits erwähnte Zwang zu kurzzyklischer Innovation massiven Druck auf die produktverantwortlichen Mitarbeiter ausübt, vor allem mit näher rückendem Markteinführungstermin. Doch der ungewisse Ausgang dieser wiederkehrenden Bewährungsprobe sollte nicht länger dem Zufall überlassen werden.

„....wir müssen den Zugang instrumentalisieren und schanen, dass wir regelmäßig solche Innovationen zusammenbringen. Damals war es eben sebr stark zufallsgetrieben. 
Wir haben gewusst, alle drei, vier Jahre brauchen wir was Nenes. " (Senior Manager, Interview)

Insofern sollte der Zugang zu neuen Produkten prozesshafter, systematischer gestaltet werden. Diesem Wunsch kam glücklicherweise das Heilsversprechen des Stage-Gate-Systems entgegen, dessen Urheber „erkannte“, dass „Produktinnovation ein Prozess ist“ und „like other processes, innovation can be managed“ (Cooper 1990, 45). Fortan begann die Sportiva, wieder unterstützt durch einen externen Berater, ihre Innovationsaktivitäten an StageGate auszurichten. Der Prozess wurde bei seiner Einführung zunächst idealtypisch erprobt, d.h. in seiner vollen Ausprägung. Doch schon mit dem Pilotprojekt, das sich letztlich als „totaler Flop“ erwies, zeigte sich, dass der Prozess in seiner lehrbuchartigen Ausgestaltung zu bürokratisch und damit zu aufwendig und ineffizient war. ${ }^{18}$ Deshalb wurde er kurzerhand „entschlackt“ und auf die branchenspezifischen Bedürfnisse der Sportiva angepasst, was Flexibilität und einen reflexiven Umgang mit den eigenen Praktiken zeigt. So weit, so gut. Eine Komponente des Stage-Gate-Konzepts von besonderer Bedeutung sind die turnusmäßigen „Gate-Meetings“. Entgegen der Regel, dass diese ausschließlich mit Senior Managern besetzt werden, die über die Allokation von Ressourcen entscheiden können, nehmen bei der Sportiva Mitarbeiter unterschiedlichster Disziplinen und Hierarchieebenen teil. Sie bieten den Mitarbeitern so (a) Gelegenheit zur Partizipation, um (mehr oder weniger) über den Fortgang der Ideen mitzuentscheiden, wie auch (b) Raum zur kreativen Weiterentwicklung und kritischen Würdigung der vorgetragenen Ideen. Vor allem das „Gate II-Meeting“19 nimmt hier eine zentrale Stellung bei der Sportiva ein, denn es dient dem „Verdichten“, „Filtern“ und „Recyclen“ von Ideen. Doch, so zumindest das Urteil eines Befragten, wurde dieses Gate Meeting immer kürzer und damit auch die Zeit, in der im Kollektiv an Ideen gefeilt werden kann. Ein anderer Mitarbeiter urteilte ähnlich skeptisch:

„Ich weiß nicht, wie man es anders gestalten könnte, aber so wirklich effizient ist es, aus meiner Sicht zumindest, nicht. Anders gesagt: Da sind viele Ideen drin, die sind aus meiner Sicht nicht mal Ideen. Das sind so ganz Kleinigkeiten und dann hockt da die Elite am Tisch." (Manager, Interview)

Das Innovationsmanagement sah sich erneut aufgrund des nicht zufriedenstellenden Outputs gezwungen, Modifikationen am System vorzunehmen. Kleinere Änderungen wie z.B. das Kerngeschäft stärker in den Fokus zu rücken und die Bewertung der „Must-Meet“Kriterien nicht mehr über die gesamten Teilnehmer zu erheben, führten zu keiner signifikanten Verbesserung. Doch trat im Verlauf dieser Untersuchung ein Hemmnis immer deutlicher in den Vordergrund:

„...unser Chef sitzt immer oben an der Kopfseite (...) das ist schon Ausdruck einer manifestierten Hierarchie irgendwo. " (Senior Manager, Interview)

„Leider hat er so eine dominante Persönlichkeit, dass keiner sich da traut, etwas zu sagen, vor allem wenn er eine bestimmte Meinung vertritt. Da sind kaum Leute, deren Persönlichkeit stark genug ist, gegen ibn was zu sagen. " (Senior Manager, Interview)

18 „Too much Bureaucracy“ scheint kein seltenes Problem bei der Implementierung des Stage-Gate-Prozesses zu sein (vgl. Cooper 2008, 221).

19 An welchem der Autor im Rahmen der Begleitforschung als passiver Beobachter teilnahm. 
Jain/Manger (vgl. 2016, 211 ff.) sehen in der Deutungshoheit, die dem hierarchisch Ranghöheren vorbehalten bleibt, eine „Differenzvernichtungsmaschine“, die soziale Interaktion spezifisch vorstrukturiert. Woher aber sollte das Innovationsmanagement nun die Kompetenz und Legitimation zur Entscheidung erhalten, den eignen Chef aus dem Meeting zu verbannen? Eine Zwickmühle, wie es im Volksmund heißt. Jedenfalls wurden sogar externe Berater engagiert, die nach pathologischen Befunden suchen sollten, denn mittlerweile sah sich die Sportiva in einer Innovationskrise. Nach einiger Zeit erkannten auch die Berater die hierarchiebedingten Hemmnisse, die auch Cooper (vgl. 2008, 219) zu den „Common Errors and Fail Points“ zählt und als „Executive Edict“ bezeichnet. Sie sprachen prompt eine konkrete (und wie sich später herausstellte, ebenso folgenreiche) Handlungsempfehlung aus:

„Topmanagement als Gate Keeper erst bei späteren Gates einsetzen. Es soll prinzipiell die Kurve der Ideenauswabl verflacht werden. Mehr unkonkrete Ideen müssen die Chance bekommen, erst in einem reiferen Stadium vor dem Topmanagement, anzutreten'." (Abschlussbericht zur Analyse der Innovationsaktivitäten der Sportiva, externe Berater)

Das Innovationsmanagement der Sportiva sah sich im Zugzwang, schließlich wird es im Kontext der Ideengenerierung als Möglichmacher verstanden. Es leistete der Berater-Empfehlung letztlich mit einer diplomatischen Lösung Folge und benannte das Meeting kurzerhand in „Gate II Scouting-Meeting “ um. Der neue Name diente dabei als Begründung für die Auslagerung der hemmenden Hierarchieebene in eine Folgebesprechung im kleinen Kreis oder mit anderen Worten für die Beibehaltung der ursprünglichen Besprechung unter Auslagerung aller anderen Teilnehmer in eine Vorbesprechung. Unausgegorene Scoutingvorschläge verschwendeten ohnehin nur die kostbare Zeit vielbeschäftigter, gehobener Führungskräfte, so zumindest die Rechtfertigung. Doch so ließ sich das Problem letztlich nicht lösen, sondern lediglich verschieben. Senge $(2001,143)$ bezeichnete diesen Effekt als Hebelprinzip: „Wir konzentrieren uns auf die Symptome, die den stärksten Druck ausüben“, vernachlässigen dabei aber, dass sich die eingetretene Verbesserung nur kurzfristig einstellt langfristig hingegen, könne sich die Sachlage sogar noch verschlimmern (vgl. Senge 2001, 83). Symptomatische Lösungen, wie die Hierarchieauslagerung, sind freilich leichter zu bewältigen als das dominante Verhalten und den autoritären Führungsstil des Chefs (als grundsätzliche, nachhaltige Lösung) zu beeinflussen. Sie zeigen womöglich auch schneller Ergebnisse und sind mehr oder weniger von persönlichen Gefahren befreit. Doch führten sie in diesem konkreten Fall letztlich nur zur Verschiebung des eigentlichen Problems. Denn es entzog dem Gate-Meeting als ungewollte Nebenwirkung in hohem Maße Entscheidungskompetenz und damit auch den Mitarbeitern die Möglichkeit zur Partizipation:

„....wenn [der Chef] nicht drin war, war das Meeting auch für die Katz, weil egal was man irgendwie diskutiert hat, war eh sinnlos, weil letztendlich kommt [er] und gibt doch überall seine Meinung dazu." (Manager, Interview)

Dass die eigentlichen Entscheidungen über die Zukunft der Ideen fortan im kleinen Kreis der Chefetage getroffen wurden, wirkte sich nach Bekanntwerden vernichtend auf die Sinnstiftung der Gate II Scouting-Meetings aus. ${ }^{20}$ Wenn man so will, ein Nullsummenspiel:

20 Zumal der Prozess den Entwicklern ohnehin schon Autonomie entzieht, indem sie nicht mehr die Möglichkeit haben, ihre Ideen in Eigenregie (weiter)zuentwickeln. 
Deutungshoheit und Redefreiheit zum Preis der Entscheidungsautonomie. Das Meeting, an dem der Autor selbst teilnehmen durfte, endete weder mit einer klaren Entscheidung über den Status und Verbleib der Ideen, noch schien dies die Teilnehmer zu interessieren. ${ }^{21}$

„Es wird ja mittlerweile nicht mehr richtig gelebt (...) Ist ein bisschen versandet." (Manager, Interview)

„Fragt Eure Berater, was ihr tun sollt. Geben sie Euch eine definitive Antwort, feuert sie!“ (March 2001, 33). Ob es hier letztlich ratsamer gewesen wäre, Marchs Handlungsmaxime rigoros zu beherzigen, bleibt ungewiss. Doch scheint sich durch die Verbannung des Chefs außerdem noch eine weitere und vor allem schwerwiegende Nebenfolge einzustellen:

„Ab einem gewissen Zeitpunkt hat niemand mehr bei uns in diese Gate-Meetings Vertrauen gehabt (...). Der [Innovationsmanager] wollte oder konnte es nicht mehr treiben, weil er nicht unterstützt wurde, weil der Output mangelhaft war. " (Senior Manager, Interview)

Die ausgegrenzte Hierarchieebene stand den institutionalisierten Innovationsaktivitäten fortan sogar entgegen, denn sie sah sich ihrer Mitbestimmung entmachtet und vor allem an der Urheberschaft und damit am Beitrag etwaiger zukünftiger Erfolge verweigert. ${ }^{22}$ So kann eine Hidden Agenda entstehen, denn offensichtlich sah sich diese Hierarchieinstanz danach veranlasst, auf anderem Wege Einfluss zu üben. Es wurde ein projektartiges Instrument installiert, das die gesamten institutionalisierten Innovationsaktivitäten aushebelt und überdies noch durch einen externen Berater geleitet wurde.

\begin{tabular}{|c|c|c|c|}
\hline & Kriterium & Ausprägung im Untersuchungsobjekt & \\
\hline \multirow{5}{*}{ 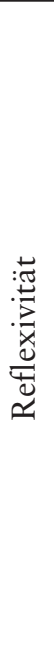 } & $\begin{array}{l}\text { Kanäle/ Grad } \\
\text { für Rückkopp- } \\
\text { lungen }\end{array}$ & $\begin{array}{l}\text { Kreative Atmosphäre um den Preis fehlender Entscheidungskompe- } \\
\text { tenz durch Ausschluss der gehobenen Führungsebene. }\end{array}$ & $\vartheta$ \\
\hline & $\begin{array}{l}\text { Fernwirkun- } \\
\text { gen }\end{array}$ & $\begin{array}{l}\text { Teilnahme sämtlicher Mitarbeiter in den Gate-Meetings möglich } \\
\text { (abhängig von benötigter Expertise/ Erfahrung). Interdisziplinäre, } \\
\text { hierarchieübergreifende Teilnehmer erhöhen Perspektivenpluralität. }\end{array}$ & o \\
\hline & $\begin{array}{l}\text { Kriterien- und } \\
\text { Zielrevision }\end{array}$ & $\begin{array}{l}\text { Hohe Anzahl der zu diskutierenden Ideen begrenzt Ausführungstie- } \\
\text { fe und Dialog über Argumente pro und kontra (auf Interdependen- } \\
\text { zen zu NeXt bzgl. der Quantitätsmaxime „je mehr, desto besser“ } \\
\text { wurde bereits eingegangen). }\end{array}$ & 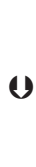 \\
\hline & $\begin{array}{l}\text { Grad der An- } \\
\text { wendung/ Aus- } \\
\text { setzung }\end{array}$ & $\begin{array}{l}\text { Steht in Konkurrenz zum „Future Product“-Projekt (Abs. 4.2.5) } \\
\text { bzw. wird von diesem sogar ausgehebelt (interner Wettbewerb). }\end{array}$ & (1) \\
\hline & $\begin{array}{l}\text { Selbstanwen- } \\
\text { dung }\end{array}$ & $\begin{array}{l}\text { „Entschlackung“, d.h. unternehmensspezifische und hierarchische } \\
\text { Anpassungen nach anfänglichen Defiziten durchgeführt. Erneute } \\
\text { Anpassungen zeigen Bereitschaft zu kontinuierlicher Reform. }\end{array}$ & (1) \\
\hline
\end{tabular}

21 Dass sich die Mitarbeiter rege beteiligten, das Meeting methodisch nicht infrage stellten, konnte auch der Anwesenheit des Forschers geschuldet sein.

22 Zumal viele Interviews zeigten, dass die Urheberschaft von Ideen keine unwesentliche Quelle intrinsischer Motivation zu sein scheint und auch zu Konflikten führen kann. Das erklärte auch die häufig beklagte Ideenpolemik: „Wirklich typisch ist, wie gesagt, dass man wirklich zuerst mal sagt: ,geht nicht, geht nicht (...) die schwarze Kappe anzieht', anstelle: ,ja cool, jetzt probieren wir das mal'.“" (Manager, Interview). 


\begin{tabular}{|c|c|c|c|}
\hline & Kriterium & Ausprägung im Untersuchungsobjekt & \\
\hline \multirow{6}{*}{ 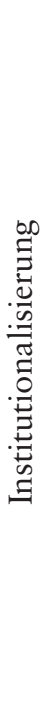 } & Legitimität & $\begin{array}{l}\text { Reputation der externen Urheber des Stage-Gate-Prozesses schaffte } \\
\text { Vertrauensvorschuss bei der Belegschaft bzgl. seiner Wirksamkeit. }\end{array}$ & 0 \\
\hline & Formalität & $\begin{array}{l}\text { Grundsätzlich prozesshafter Charakter vereinheitlicht und verein- } \\
\text { facht Einführung/ Umsetzung neuer Ideen. }\end{array}$ & 0 \\
\hline & & $\begin{array}{l}\text { Systematisches Vorgehen zur Entscheidungsfindung über das weite- } \\
\text { re Vorgehen mit den Ideen findet aufgrund zeitlicher Kapazitäts- } \\
\text { engpässe nur sporadisch Anwendung. }\end{array}$ & (1) \\
\hline & Faktizität & $\begin{array}{l}\text { Der mittlerweile zehnjährige Bestand begünstigt den Erhalt. Jedoch } \\
\text { sind Erfolg und Misserfolg des prozessualen Arrangements nach } \\
\text { wie vor im Innovationsmanager personifiziert, dem Initiator. }\end{array}$ & (1) \\
\hline & Signifikanz & $\begin{array}{l}\text { Mit Auslagerung der „Chefetage“ sank nicht nur die Bedeutung } \\
\text { des Prozesses, es entwickelte sich ein oppositionelles Lager. Mit } \\
\text { Einführung des „Future Product“-Projekts wird der Prozess zuneh- } \\
\text { mend seiner Daseinsberechtigung enthoben. }\end{array}$ & (1) \\
\hline & $\begin{array}{l}\text { Durchset- } \\
\text { zungsmecha- } \\
\text { nismen }\end{array}$ & $\begin{array}{l}\text { Nichteinhaltung der Gate-Bedingungen („Deliverables“) sanktio- } \\
\text { niert die Idee bzw. das Projekt und damit indirekt den Projektleiter } \\
\text { (mitunter den Ideengeber). }\end{array}$ & $\Rightarrow$ \\
\hline
\end{tabular}

Tabelle 6: Reflexivität und ihre Institutionalisierung: „Stage-Gate-Prozess®“

Auch an dieses Instrument lässt sich also keine bedingungslose Wirksamkeit knüpfen. Die verhältnismäßig strikte Institutionalisierung wurde vor allem vom ungeplanten Verlust der Entscheidungskompetenz konterkariert. Obgleich der Prozess äußerst anpassungsfähig installiert wurde, stellten sich mit dem unternehmensstrukturellen Setting (Hierarchie, etc.) schwerwiegende Komplikationen ein.

\subsection{5 „Future Product“-Projekt}

Als eines unter vielen und auch weil die Belegschaft noch nicht durchgängig damit betraut wurde, fiel das Projekt bei der Untersuchung zunächst gar nicht auf. ${ }^{23}$ Erst als die Projektziele angesprochen wurden, zeigte sich, dass es dazu dient, alternative Zukünfte zu entwickeln und damit auch als (potenziell) reflexive Institution konzipiert werden kann (vgl. Moldaschl 2011, 41; Kriterien für das Vorhandensein institutioneller Reflexivität). Die Ziele wurden dabei so leicht verständlich wie prägnant formuliert, als...

„...dass wir eine neue Technologie mit einem spürbaren Unterschied auf den Markt bringen können, wenn sie benötigt wird. Es ist ein ganz eigenartiges Projekt, weil es nicht zeitlich befristet ist. " (Senior Manager, Interview)

„Future-[Product] hat eigentlich im Prinzip kein Enddatum, aber irgendwann muss was kommen (...) da muss was Radikales rauskommen. " (Senior Manager, Interview)

Das Projekt wurde mit dem Zweck geboren, die bisweilen inkrementellen Neuerungen mit einem diskontinuierlichen Technologiesprung zu unterbrechen, also explizit radikale Neu-

23 „Future Product“-Projekt ist ein Kunstwort zur Wahrung der Anonymität des untersuchten Unternehmens. 
erungen hervorzubringen. Die Formulierung dieses doch recht ambitionierten Projektziels könnte dabei kaum mehr Kontingenz eröffnen. Doch offensichtlich wird das den eben beschriebenen, dauerhaft angelegten, prozessunterstützen, institutionalisierten Innovationsaktivitäten nicht zugetraut:

„Das heißt, wir waren nicht in der Lage, durch unseren etablierten Prozess zu diesem Ergebnis zu kommen. Und weil wir irgendwas brauchten, haben wir gesagt, jetzt gehen wir einen anderen Weg. " (Senior Manager, Interview)

„Irgendwie brauchen wir die radikalen Innovationen. Die muss man dann parallel machen." (Senior Manager, Interview)

Es spricht dem institutionalisierten Innovationssystem (bestehend aus den vier zuvor genannten Komponenten) schlagartig die Berechtigung und damit den Sinn ab, genau das zu tun, was im Unternehmen die meiste Anerkennung stiftet und wozu es eigentlich ins Leben gerufen wurde: radikale Modernisierung. Nun, wenn organisationale Modernisierungsbemühungen im Forschungsfeld von Exploration und Exploitation anhand ihrer Veränderungsintensität dichotom (inkrementell vs. radikal) modelliert werden, dann können die dafür institutionalisierten Praktiken, Regeln und Verfahren auch im Hinblick auf ihre potenzielle und tatsächliche Reflexivität analysiert werden. Denn beide Initiativen (das etablierte Verfahren und dieses Projekt) lassen sich vor dem Hintergrund des Konzeptes der Ambidextrie als eine spezifische Art der Installation exploitativer und explorativer Tätigkeiten verstehen. Mit einer Besonderheit allerdings: Die beiden Aktivitäten konkurrieren nicht nur in ihrer zugrundeliegenden Denk- und Herangehensweise um knappe Ressourcen (wie im Diskurs breit diskutiert), ${ }^{24}$ sondern in diesem Fall auch um ihre Daseinsberechtigung, unterstellte man ihnen eine redundante Zweckausrichtung. „Future Product“ fungiert als konkurrierende Alternative zum institutionalisierten Innovationssystem, quasi als (bewusst) induzierte Störung, mit den Worten Brunner et al.'s $(2008,1)$ als „Perturbation“: „novel stimuli that disrupt the execution of specialized routines“. Dieses konfligierende und schwammige Verhältnis erzeugt strukturelle wie mentale Spannungen und begünstigt damit erneut die Entstehung „organisationaler Dissonanz“ (vgl. Jochims 2010, 59 ff.). Dem Innovationsmanager bleibt unter diesen widersprüchlichen Erwartungshaltungen schließlich nichts anderes übrig, als eine Ko-Existenz zu ermöglichen, möchte er seinen Fortbestand nicht gefährden.

Ob diese eigentümliche Konfiguration betrieblicher Modernisierung durch den provozierten Wettbewerb zwischen beiden reflexiven Institutionen vor der Gefahr einer potenziellen Überbetonung explorativer bzw. exploitativer Aktivitäten schützen soll, vor welchen häufig gewarnt wird (vgl. Levitt/March 1988, 322 oder Levinthal/March 1993, 105 f.), oder ob sie der bloßen Durchsetzung von Individualinteressen dient, kann nicht zweifelsfrei geklärt werden. Weshalb aber die Ausgestaltung in dieser konkurrierenden Form mündete, soll einem Erklärungsversuch unterzogen werden, der wieder multikausalistisch ausfällt: Erstens bieten temporäre Arrangements in Projektform, die erst verspätet als Reaktion auf Unzufriedenheit installiert werden als unbefleckter Gegenentwurf kaum Angriffsfläche für Kritik. Sie haben bislang weder Kosten verursacht, noch sind sie emotional negativ aufgeladen. Zweitens haben Institutionen die Eigenschaft, dass sie, einmal installiert, hohe Beharrungskräfte entwickeln können (vgl. unter vielen Scott 2001, 48), selbst wenn ihre Ergebnisse nicht wie

24 Siehe March (1991), Birkinshaw/Gibson (2004), Konlechner/Güttel (2009), Hobus/Busch (2011). 
gewünscht ausfallen - erst recht wenn sie in Zeiten des obligatorischen Wandels normative Kriterien populärer Innovationspraktiken erfüllen (vgl. Meyer/Rowan 1977, 343 ff.). Mitunter müsste mehr Energie in die Auflösung von Teilen des etablierten Innovationssystems investiert werden als in die Entfaltung neuer Alternativen. Das „Future Product“-Projekt bietet sozusagen den Weg eines geringeren Widerstands. Drittens ist doch die Krux an radikalen Innovationen, dass der Seltenheitswert in der Natur ihrer Sache liegt. Erst weil sie einer Periode inkrementeller Veränderungen folgen, können sie als radikal wahrgenommen werden. Eine etablierte Einrichtung, die aber aufgrund ihrer Reife und ihres Alters auch schon zahlreiche inkrementelle Neuerungen hervorbrachte in der Rolle einer „Deus ex Machina “ - was könnte noch abwegiger sein?

\begin{tabular}{|c|c|c|c|}
\hline & Kriterium & Ausprägung im Untersuchungsobjekt & \\
\hline \multirow{5}{*}{ 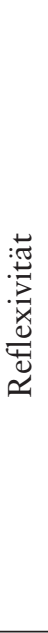 } & $\begin{array}{l}\text { Kanäle/ Grad } \\
\text { für Rückkopp- } \\
\text { lungen }\end{array}$ & $\begin{array}{l}\text { Projektleitung durch externen Berater. Projekt startet entkoppelt } \\
\text { von bestehendem Ideenpool. }\end{array}$ & $\vartheta$ \\
\hline & Fernwirkungen & $\begin{array}{l}\text { Kleiner, stark selektierter Teilnehmerkreis, um eine effiziente Ab- } \\
\text { wicklung sicherzustellen, reduziert aber gleichzeitig konstruktive } \\
\text { Kritik an Entscheidungen und Vorgehensweise. }\end{array}$ & (1) \\
\hline & $\begin{array}{l}\text { Kriterien- und } \\
\text { Zielrevision }\end{array}$ & $\begin{array}{l}\text { Höchstmögliche Freiheitsgrade in Zieldefinition und Vorgehen, je- } \\
\text { doch bei hohem Zielanspruch (Gefahr psychischer Überlastung). }\end{array}$ & 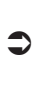 \\
\hline & $\begin{array}{l}\text { Grad der An- } \\
\text { wendung/ Aus- } \\
\text { setzung }\end{array}$ & $\begin{array}{l}\text { Steht in Konkurrenz zum etablierten Innovationsmanagement. Er- } \\
\text { gebnisse werden gegeneinander aufgewogen (interner Wettbewerb). } \\
\text { Das setzt Involvierte auf beiden Seiten unter Druck (widersprüchli- } \\
\text { che Arbeitsanforderungen). }\end{array}$ & (1) \\
\hline & $\begin{array}{l}\text { Selbstanwen- } \\
\text { dung }\end{array}$ & $\begin{array}{l}\text { Kein Kanal für Kritik oder Feedback am Verfahren vorgesehen. Als } \\
\text { unbefleckter Gegenentwurf zum etablierten Innovationsmanage- } \\
\text { ment jedoch frei von Altlasten. }\end{array}$ & (1) \\
\hline \multirow{5}{*}{ 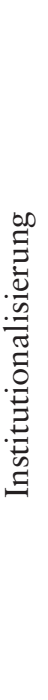 } & Legitimität & $\begin{array}{l}\text { Projekt ist der Belegschaft nur teilweise bekannt (typisches „Maul- } \\
\text { wurf-Projekt“). Damit soll es wenig Angriffsfläche für Kritik und } \\
\text { Diskussionen bieten: „Viele Köche verderben den Brei“. Top-Ma- } \\
\text { nagement-Unterstützung wirkt jedoch geringer Akzeptanz aufgrund } \\
\text { fehlender Kommunikation entgegen. }\end{array}$ & (1) \\
\hline & Formalität & $\begin{array}{l}\text { Höchste Freiheitsgrade bzgl. Abwicklung, Methoden und Zielvorga- } \\
\text { ben. Das birgt jedoch auch die Gefahr psychischer Überlastung. }\end{array}$ & 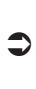 \\
\hline & Faktizität & $\begin{array}{l}\text { Konkurriert mit etabliertem Innovationssystem um Daseinsberechti- } \\
\text { gung und Ressourcenzuwendung als noch unbefleckter, junger Ge- } \\
\text { genentwurf. }\end{array}$ & (1) \\
\hline & Signifikanz & $\begin{array}{l}\text { Großzügige Mittel- und Aufmerksamkeitszuwendung schafft zwar } \\
\text { Vertrauen in die Initiative, bremst jedoch (relativ dazu) alternative } \\
\text { Initiativen mit gleicher Zielausrichtung (etabliertes Innovationssys- } \\
\text { tem). Das begünstigt organisationale Dissonanz, sowie Interessen- } \\
\text { und Rollenkonflikte. }\end{array}$ & $\vartheta$ \\
\hline & $\begin{array}{l}\text { Durchsetzungs- } \\
\text { mechanismen }\end{array}$ & $\begin{array}{l}\text { Implizite Durchsetzung über Top-Management-Commitment macht } \\
\text { reglementierte Sanktionen obsolet. }\end{array}$ & $\Rightarrow$ \\
\hline
\end{tabular}

Tabelle 7: Reflexivität und ihre Institutionalisierung: „Future Product“-Projekt 


\section{Konklusion}

In dieser explorativen Untersuchung wurde die Viabilität organisationaler Arrangements, die der Modernisierung dienen, in Form einer Fallstudie empirisch analysiert. Dabei wurden jedoch nicht nur die Ausprägungen des Lernens operationalisiert, sondern auch der Sinnbezug in Form der Institutionalisierung.

\subsection{Konzeptionelle Schlussfolgerungen}

Aus konzeptioneller Sicht konnte mit der explorativen Fallstudie herausgearbeitet werden, dass die Art und Weise der Institutionalisierung keinen unwesentlichen Einfluss auf die Wirksamkeit (operationalisiert als „Viabilität“) organisationaler Lernaktivitäten (also des reflexiven Moments) hat. Reflexivität und ihre Institutionalisierung, verstanden als zwei gegenläufige Eigenschaften organisationaler Modernisierungsbemühungen, kann dabei die Charakteristik einer multiplikativen Beziehung unterstellt werden. Ihre Wirksamkeit (verstanden als das arithmetische Produkt) entfaltet sich kaum, wenn auch nur eine von beiden (Variablen) schwache Ausprägung erfährt. ${ }^{25}$ Damit liegt eine „Verschränkung“ vor, d.h., dass institutionelle Reflexivität nicht mit nur einer der beiden Komponenten beschrieben werden kann. So zeigten Arrangements mit stark ausgeprägter Institutionalisierung wenig Wirkung, wenn reflexive Kriterien vernachlässigt wurden. Sie verkümmerten zu billigend in Kauf genommener "Makulatur“ und erhielten Legitimation im Sinne Lubmanns (1969) allenfalls durch Verfahren, nicht aber Modernisierung. Trotz hoher Grade an Reflexivität blieben Arrangements dagegen nahezu ergebnislos bei nur schwacher Institutionalisierung. Erst „, vor dem Hintergrund habitualisierten Handelns öffnet sich ein Vordergrund für Einfall und Innovation“ (Berger/Luckmann 2004, 57). So belasten sie Akteure mit der keineswegs allseits beliebten Aufforderung, Etabliertes infrage zu stellen, entlasten sie demgegenüber aber teils nur unzureichend von der Bürde der Rechtfertigung vor dem Hintergrund normativer Verhaltenserwartungen. Dass es für Akteure kein leichtes Unterfangen ist, den Status quo infrage zu stellen (besonders ohne die Unterstützung der Institutionalisierung), erkannte bereits Schumpeter (1997, 125 f.): Denn „[e]s ist nicht nur sachlich schwieriger und etwas Anderes, Neues zu tun, als das Gewohnte und Erprobte“, es entsteht auch „Gegendruck, mit dem die soziale Umwelt jedem begegnet, der überhaupt oder speziell wirtschaftlich etwas Neues tun will“. „Schon das bloße Erstaunen über die Abweichung, schon das bloße Konstatieren derselben übt einen Druck auf den Einzelnen aus" (Schumpeter 1997, 126 f.).

\subsection{Diskussion und Limitation}

Mit der ausgebauten Operationalisierung institutioneller Reflexivität gewährt dieser Beitrag Einblicke in eine weitere Facette organisationalen Lernens - einem komplexen Untersuchungsgegenstand, der Management- und Organisationsforscher seit Jahrzehnten beschäftigt und voraussichtlich auch noch weiterhin beschäftigen wird. Wie die Fallstudie verdeutlichte, erschließt sich die Wirksamkeit organisationaler Lernaktivitäten nicht durch

25 Die Analogie zur multiplikativen Beziehung im arithmetischen Sinne eignet sich hier besonders, weil sie verdeutlicht, dass das Produkt mit zunehmender Faktorendifferenz abnimmt, das Produkt also selbst bei extrem hohen Werten eines Faktors durch niedrige Werte des anderen Faktors kollabieren würde, d.h. ein Arrangement, das noch so reflexiv ausgeführt wird, mit einer inadäquaten Institutionalisierung kaum die erwünschte Wirkung erzielen wird - und umgekehrt. 
bloße Intuition. Umfangreich und elaboriert von den Verantwortlichen ausgeführt, ließ das gesamte Arrangement (das Innovationssystem der Sportiva) zunächst keine Zweifel an seiner Wirksamkeit. Erst mit der tiefgreifenden qualitativen Analyse der Installation, des Gebrauchs, der vorherrschenden Stimmung wie auch der unternehmenskulturellen Einbettung, wurde allmählich deutlich, dass sich einige der reflexiven Institutionen von ihren originären (bzw. beabsichtigten) Zwecken zu emanzipieren begannen, zumindest jedoch unbeabsichtigte Nebenfolgen verursachten. Ferner konnten sogar unerwünschte Wechselwirkungen zwischen den formal separierten Initiativen herausgearbeitet werden, obgleich sie sich eigentlich ergänzen sollten, statt in Konkurrenz zu treten. Das führt nicht nur zur Argumentationsfigur des soziologischen Neoinstitutionalismus, der bei Abweichungen zwischen zweckrationaler Begründung bewusst geschaffener Institutionen und ihrem tatsächlichen Gebrauch ansetzt, sondern auch zu systemischen (u.a. individual-psychologische und systemtheoretische) und strategischen (u.a. mikropolitische und institutionalistische) Erklärungstypen (vgl. Moldaschl 2010, 85), wie gezeigt werden konnte. Aufgrund dieser Vielfalt wurde die „Instrumentalität“ installierter Institutionen bewusst nicht als Operationalisierungskriterium eingeführt, denn eher als „Residualkategorie“ belassen, der im Rahmen sozioökonomischer Begleitforschung vollste Aufmerksamkeit zu widmen ist.

Anspruch dieser sozioökonomischen Untersuchung war es herauszuschälen, oder: zu demonstrieren, dass und warum eine rein „technische“, nur auf das Registrieren organisatorischer Regeln und Formen bezogene Analyse von „(Change-)Capabilities“ nicht sehr weit führt. Und damit: Warum die im verwendeten Ansatz hervorgehobene Sinnebene der Organisationsgestaltung so wichtig ist. Andernfalls registriert man nur „geistlose“ Handlungsanweisungen, und hält diese dann womöglich für das Knochengerüst lebendiger Fähigkeiten oder „Capacities“. Solche wären nicht nur ihrer (sozialen) Einbettung und Kontextabhängigkeit enthoben, generalisierte Empfehlungen (häufig als „Best Practices“ ausgewiesen) suggerierten grenzen- und folgenlose Übertragbarkeit auf andere Unternehmen. Auch wenn doch in der Praxis konkrete Lösungsvorschläge in „komplexitätsreduktionskommerzialistischem Gewand“ herzlich willkommen sind und selbst der Akt der Erfolgszuschreibung solcher Reformen nicht selten seiner Subjektivität befreit wird.

\section{Literaturverzeichnis}

Altschuller, G. S. (1986): Erfinden - Wege zur Lösung technischer Probleme, 2. Aufl.

Argyris, C./Schön, D. A. (1974): Theory in practice: Increasing professional effectiveness, 1. Aufl., San Francisco.

Argyris, C./Schön, D. A. (2006): Die lernende Organisation: Grundlagen, Methode, Praxis, 3. Aufl., Stuttgart.

Baumeister, R. F. (1982): A self-presentational view of social phenomena, in: Psychological Bulletin, 91. Jg., Nr. 1, S. 3-26.

Berger, P. L./Luckmann, T. (2004): Die gesellschaftliche Konstruktion der Wirklichkeit: Eine Theorie der Wissenssoziologie, 20. Aufl., Frankfurt am Main.

Birkinshaw, J./Gibson, C. B. (2004): Building Ambidexterity into an Organization, in: MIT Sloan Management Review, 45. Jg., Nr. 4, S. 47-55.

Bogumil, J./Ebinger, F./Holtkamp, L./Seuberlich, M. (2016): Institutionelle Reflexivität in der öffentlichen Verwaltung, in: Moldaschl, M./ Manger, D. (Hrsg.): Im Spiegel der Organisation: Innovationsfähigkeit durch institutionelle Reflexivität, München, Mering, S. 63-86. 
Bohnsack, R. (2014): Rekonstruktive Sozialforschung: Einführung in qualitative Methoden, 9. Aufl., Opladen.

Brunner, D. J./Staats, B. R./Tushman, M. L./Upton, D. M. (2008): Wellsprings of Creation: Perturbation and the Paradox of the Highly Disciplined Organization, Working Paper No. 09-011, Cambridge, Mass.

Brunsson, N./Olsen, J. P. (1993): The Reforming Organization, London, New York.

Campbell, D. T. (1960): Blind variation and selective retentions in creative thought as in other knowledge processes, in: Psychological Review, 67. Jg., Nr. 6, S. 380-400.

Cohen, W. M./Levinthal, D. A. (1990): Absorptive Capacity: A New Perspective on Learning and Innovation, in: Administrative Science Quarterly, 35. Jg., Nr. 1, S. 128-152.

Cooper, R. G. (1990): Stage-gate systems: A new tool for managing new products, in: Business Horizons, 33. Jg., Nr. 3, S. 44-54.

Cooper, R. G. (2008): Perspective: The Stage-Gate ${ }^{\circledR}$ Idea-to-Launch Process - Update, What's New, and NexGen Systems, in: Journal of Product Innovation Management, 25. Jg., Nr. 3, S. 213-232.

Covey, S./McChesney, C./Huling, J. (2016): The 4 Disciplines of Execution: Achieving Your Wildly Important Goals.

Deephouse, D. L./Suchman, M. (2008): Legitimacy in Organizational Institutionalism, in: Greenwood, R./Oliver, C./Suddaby, R./ Sahlin-Andersson, K. (Hrsg.): The SAGE handbook of Organizational Institutionalism, Los Angeles, London, New Delhi, Singapore, S. 49-77.

Dietl, H. (1993): Institutionen und Zeit, Tübingen.

DiMaggio, P. J./Powell, W. W. (1983): The Iron Cage Revisited: Institutional Isomorphism and Collective Rationality in Organizational Fields, in: American Sociological Review, 48. Jg., Nr. 2, S. 147-160.

Durkheim, É. (1965): Die Regeln der soziologischen Methode, 2. Aufl., Neuwied, Berlin.

Eder, K. (1997): Institution, in: Wulf, C. (Hrsg.): Vom Menschen: Handbuch historische Anthropologie, Weinheim, S. 159-168.

Fader, P. (2012): Customer Centricity: Focus on the Right Customers for Strategic Advantage, New York.

Farjoun, M. (2010): Beyond Dualism: Stability and Change as a Duality, in: Academy of Management Review, 35. Jg., Nr. 2, S. 202-225.

Feldman, M. S./Pentland, B. T. (2003): Reconceptualizing Organizational Routines as a Source of Flexibility and Change, in: Administrative Science Quarterly, 48. Jg., Nr. 1, S. 94-118.

Festinger, L. (1957): A Theory of Cognitive Dissonance, 1. Aufl., Stanford.

Feyerabend, P. (1986): Wider den Methodenzwang, 1. Aufl., Frankfurt am Main.

Flick, U. (2012): Qualitative Sozialforschung: Eine Einführung, 5. Aufl., Reinbek bei Hamburg.

Gibson, C. B./Birkinshaw, J. (2004): The Antecedents, Consequences, and Mediating Role of Organizational Ambidexterity, in: Academy of Management Journal, 47. Jg., Nr. 2, S. 209-226.

Giddens, A. (1984): The Constitution of Society: Outline of the Theory of Structuration, Cambridge.

Glasersfeld, E. von (1992a): Anpassung und Überlebensfähigkeit, in: Glasersfeld, E. von/ Köck, W. K. (Hrsg.): Wissen, Sprache und Wirklichkeit: Arbeiten zum radikalen Konstruktivismus, Braunschweig, S. 80-85. 
Glasersfeld, E. von (1992b): Die Begriffe der Anpassung und Viabilität in einer radikal konstruktivistischen Erkenntnistheorie, in: Glasersfeld, E. von/ Köck, W. K. (Hrsg.): Wissen, Sprache und Wirklichkeit: Arbeiten zum radikalen Konstruktivismus, Braunschweig, S. 137-143.

Golden, B. R. (1997): Further Remarks on Retrospective Accounts in Organizational and Strategic Management Research, in: Academy of Management Journal, 40. Jg., Nr. 5, S. 1243-1252.

Greenwood, R./Raynard, M./Kodeih, F./Micelotta, E. R./Lounsbury, M. (2011): Institutional Complexity and Organizational Responses, in: Academy of Management Annals, 5. Jg., Nr. 1, S. 317-371.

Hallensleben, T. (2015): Reflexive Prävention: Kriterien und Befunde zur nachhaltigen Organisation wissensintensiver Arbeit, in: Zeitschrift Führung + Organisation, 84. Jg., Nr. 5, S. 331-338.

Hallensleben, T. (2016): Veränderung in Unsicherheit: Von der Suche nach Gewissheit im organisationalen Wandel, in: Moldaschl, M./ Manger, D. (Hrsg.): Im Spiegel der Organisation: Innovationsfähigkeit durch institutionelle Reflexivität, München, Mering, S. 249-280.

Hallensleben, T./Jain, A. K. (2016): „Wir müssen hier schnell konstruieren“: Diskurs und institutionelle Reflexivität, in: Moldaschl, M./ Manger, D. (Hrsg.): Im Spiegel der Organisation: Innovationsfähigkeit durch institutionelle Reflexivität, München, Mering, S. 303-334.

Hallensleben, T./Wörlen, M./Moldaschl, M. (2015): Institutional and personal reflexivity in processes of organisational learning, in: International Journal of Work Innovation, 1. Jg., Nr. 2, S. 185207.

Hanson, N. R. (1958): Patterns of discovery: An inquiry into the conceptual foundations of science, Cambridge.

Hedberg, B. (1981): How Organizations Learn and Unlearn, in: Nystrom, P. C./ Starbuck, W. H. (Hrsg.): Handbook of Organizational Design, Oxford, New York, S. 3-37.

Hobus, B./Busch, M. W. (2011): Organisationale Ambidextrie, in: Die Betriebswirtschaft, 71. Jg., Nr. 2, S. 189-193.

Hollis, M. (1995): Soziales Handeln: Eine Einführung in die Philosophie der Sozialwissenschaft, Berlin.

Irle, M. (1975): Lehrbuch der Sozialpsychologie, Göttingen.

Jackall, R. (2010): Moral mazes: The world of corporate managers, 20. Aufl.

Jain, A. K./Hallensleben, T./Manger, D. (2013): Reflexivity and Innovation: Conflicting Counterparts?, in: International Journal of Innovation and Technology Management, 10. Jg., Nr. 6, 1340026-1-1340026-21.

Jain, A. K./Manger, D. (2016): Reflexivität und Differenz: Die deflexive Schließung der Offenheit und die reflexive Öffnung der Abgeschlossenheit (illustriert anhand zweier Fallbeispiele), in: Moldaschl, M./ Manger, D. (Hrsg.): Im Spiegel der Organisation: Innovationsfähigkeit durch institutionelle Reflexivität, München, Mering, 211-238.

Jain, A. K./Moldaschl, M./Manger, D./Hallensleben, T. (2016): Reflexivität durch Verfahren: Zum Zusammenhang zwischen Reflexivität, Innovation und dem Einsatz von Management-Tools, in: Moldaschl, M./ Manger, D. (Hrsg.): Im Spiegel der Organisation: Innovationsfähigkeit durch institutionelle Reflexivität, München, Mering, S. 149-210.

Jochims, T. (2010): Personalpolitik in mittelständischen Unternehmen: Personalpolitische Konfigurationen und organisationale Dissonanz, München, Mering.

Kahneman, D. (2012): Schnelles Denken, langsames Denken, München.

Kaplan, R. S./Norton, D. P. (1992): The balanced scorecard: Measures that drive performance, in: Harvard Business Review, 70. Jg., Nr. 1, S. 71-79. 
Kelley, T./Littman, J. (2002): Das IDEO Innovationsbuch: Wie Unternehmen auf neue Ideen kommen, 1. Aufl., München.

Keum, D. D./See, K. E. (2017): The Influence of Hierarchy on Idea Generation and Selection in the Innovation Process, in: Organization Science, 28. Jg., Nr. 4, S. 653-669.

Kieser, A. (1997): Rhetoric and Myth in Management Fashion, in: Organization, 4. Jg., Nr. 1, S. 4974.

Kirsch, W./Seidl, D./van Aaken, D. (2010): Evolutionäre Organisationstheorie, Stuttgart.

Kleinschmidt, E. J./Brentani, U. de/Salomo, S. (2007): Performance of Global New Product Development Programs: A Resource-Based View, in: Journal of Product Innovation Management, 24. Jg., Nr. 5, S. 419-441.

Koch, J. (2009): Innovation, organisationale Routinen und strategische Pfade, in: Zeitschrift für Management, 4. Jg., Nr. 3, S. 189-208.

Koch, S./Schemmann, M. (Hrsg.) (2009): Neo-Institutionalismus in der Erziehungswissenschaft: Grundlegende Texte und empirische Studien, 1. Aufl., Wiesbaden.

Konlechner, S. W./Güttel, W. H. (2009): Kontinuierlicher Wandel mit Ambidexterity: Vorhandenes Wissen nutzen und gleichzeitig neues entwickeln, in: Zeitschrift Führung + Organisation, 78. Jg., Nr. 1, S. 45-53.

Lane, P. J./Salk, J. E./Lyles, M. A. (2001): Absorptive capacity, learning, and performance in international joint ventures, in: Strategic Management Journal, 22. Jg., Nr. 12, S. 1139-1161.

Levitt, B./March, J. G. (1988): Organizational Learning, in: Annual Review of Sociology, 14. Jg., S. 319-340.

Lichtenthaler, U. (2009): Absorptive Capacity, Environmental Turbulence, and the Complementarity of Organizational Learning Processes, in: Academy of Management Journal, 52. Jg., Nr. 4, S. 822-846.

Liebold, R./Trinczek, R. (2009): Experteninterview, in: Kühl, S. (Hrsg.): Handbuch Methoden der Organisationsforschung: Quantitative und qualitative Methoden, Wiesbaden, S. 32-56.

Lin, M. J. J./Chuang, M. Y./Wei, K. L. (2014): Relationships between collective learning, absorptive capacity, and innovation performance, in: International Journal of Innovation and Learning, 16. Jg., Nr. 3, S. 338-352.

Lubatkin, M. H./Simsek, Z./Ling, Y./Veiga, J. F. (2006): Ambidexterity and Performance in Small-to Medium-Sized Firms: The Pivotal Role of Top Management Team Behavioral Integration, in: Journal of Management, 32. Jg., Nr. 5, S. 646-672.

Lubmann, N. (1969): Legitimation durch Verfahren, Neuwied, Berlin.

Manger, D. (2016): Die Reflexivität institutioneller Reflexivität: Zum Umgang mit Unsicherheit und Risiko in organisationalen Veränderungsprozessen, in: Moldaschl, M./ Manger, D. (Hrsg.): Im Spiegel der Organisation: Innovationsfähigkeit durch institutionelle Reflexivität, München, Mering, S. 281-302.

March, J. G. (1991): Exploration and Exploitation in Organizational Learning, in: Organization Science, 2. Jg., Nr. 1, S. 71-87.

March, J. G. (2001): Wenn Organisationen wirklich intelligent werden wollen, müssen sie lernen, sich Torheiten zu leisten!, in: Bardmann, T. M./ Groth, T. (Hrsg.): Zirkuläre Positionen 3 - Organisation, Management und Beratung, Wiesbaden, S. 21-33.

Meyer, J. W./Rowan, B. (1977): Institutionalized Organizations: Formal Structure as Myth and Ceremony, in: American Journal of Sociology, 83. Jg., Nr. 2, S. 340-363. 
Meyer, M./Reutterer, T. (2007): Sampling-Methoden in der Marktforschung: Wie man Untersuchungseinheiten auswählen kann, in: Buber, R./ Holzmüller, H. H. (Hrsg.): Qualitative Marktforschung: Konzepte - Methoden - Analysen, Wiesbaden, S. 229-246.

Mezias, J. M./Starbuck, W. H. (2003): Studying the Accuracy of Managers' Perceptions: A Research Odyssey, in: British Journal of Management, 14. Jg., Nr. 1, S. 3-17.

Mishra, A. A./Shah, R. (2009): In union lies strength: Collaborative competence in new product development and its performance effects, in: Journal of Operations Management, 27. Jg., Nr. 4, S. 324-338.

Moldaschl, M. (2005a): Audit-Explosion und Controlling-Revolution: Zur Verstetigung und Verselbständigung reflexiver Praktiken in der Wirtschaft, in: Soziale Welt, 56. Jg., 2/3, S. 267-294.

Moldaschl, M. (2005b): Institutionelle Reflexivität: Zur Analyse von „Change“ im Bermuda-Dreieck von Modernisierungs-, Organisations- und Interventionstheorie, in: Faust, M. (Hrsg.): Die „Organisation“ der Arbeit, München, S. 355-382.

Moldaschl, M. (2006): Innovationsfähigkeit, Zukunftsfähigkeit, Dynamic Capabilities: Moderne Fähigkeitsmystik und eine Alternative, in: Schreyögg, G./ Conrad, P. (Hrsg.): Management von Kompetenz, Wiesbaden, S. 1-36.

Moldaschl, M. (Hrsg.) (2007a): Immaterielle Ressourcen: Nachhaltigkeit von Unternehmensführung und Arbeit I, 2. Aufl., München u.a.

Moldaschl, M. (2007b): Veränderungsrhetorik und Wettbewahren: Indikatoren für die Fähigkeit von Organisationen, sich zu erneuern, in: Organisationsentwicklung, 26. Jg., Nr. 4, S. 34-43.

Moldaschl, M. (2009): Erkenntnisbarrieren und Erkenntnisverhütungsmittel: Warum siebzig Prozent der Changeprojekte scheitern, in: von Ameln, F./Kramer, J./ Stark, H. (Hrsg.): Organisationsberatung beobachtet: Hidden Agendas und blinde Flecke, Wiesbaden, S. 301-307.

Moldaschl, M. (2010): Depistemologie des Organisationslernens: Beiträge zur Wissenschaft des Scheiterns, in: Heidsiek, C. (Hrsg.): Organisationslernen im 21. Jahrhundert. Festschrift für Harald Geißler, Frankfurt, M., Berlin, Bern, Bruxelles, New York, Oxford, Wien, S. 81-92.

Moldaschl, M. (2011): Warum Gazellen nachts nicht leuchten: Evolutorische Theorie der Unternehmung statt normativer Modelle des Kompetenzmanagements, in: Barthel, E./Hanft, A./Hasebrook, J./ Baltes, G. (Hrsg.): Integriertes Kompetenzmanagement: Innovationsstrategien als Aufgabe der Organisations- und Personalentwicklung, Münster, S. 15-51.

Moldaschl, M. (2013): Ressourcenkulturen messen, bewerten und verstehen: Ein Analyseansatz der Evolutorischen Theorie der Unternehmung., in: Klinke, S./ Rohn, H. (Hrsg.): RessourcenKultur: Vertrauenskulturen und Innovationen für Ressourceneffizienz im Spannungsfeld normativer Orientierung und betrieblicher Praxis, Baden-Baden, S. 111-139.

Moldaschl, M. (2015): Die Einbettung der Sozioökonomik: Paradigmatische Grundlagen und Transdisziplinarität, in: Hedtke, R. (Hrsg.): Was ist und wozu Sozioökonomie?, Wiesbaden, S. 125157.

Moldaschl, M./Hallensleben, T./Breßler, J./Wörlen, M. (2012): How to get off innovation capabilities by change programs? Theory and case study, in: Proceedings of the Intern. Symposium on Innovation Methods and Innovation Management Chemnitz, Germany, S. 1-10.

Nelson, R. R./Winter, S. G. (1982): An evolutionary theory of economic change, Cambridge.

North, D. C. (1990): Institutions, institutional change, and economic performance, Cambridge, New York.

North, D. C. (1991): Institutions, in: Journal of Economic Perspectives, 5. Jg., Nr. 1, S. 97-112.

North, D. C. (1992): Institutionen, institutioneller Wandel und Wirtschaftsleistung, Tübingen. 
Parsons, T./Turner, B. S. (1991): The Social System, London.

Pavlou, P. A./El Sawy, O. A. (2011): Understanding the Elusive Black Box of Dynamic Capabilities, in: Decision Sciences, 42. Jg., Nr. 1, S. 239-273.

Perrin, D./Wyss, V. (2016): In die Geschichten erzählen: Die Analyse von Narration in öffentlicher Kommunikation, in: Averbeck-Lietz, S./ Meyen, M. (Hrsg.): Handbuch nicht standardisierte Methoden in der Kommunikationswissenschaft, Wiesbaden, S. 241-255.

Plumpe, W. (2003): Die Unwahrscheinlichkeit des Jubiläums - oder: warum Unternehmen nur historisch erklärt werden können, in: Jahrbuch für Wirtschaftsgeschichte / Economic History Yearbook, 44. Jg., Nr. 1, S. 143-156.

Popper, K. R. (1977): Falsche Propheten: Hegel, Marx und die Folgen, 5. Aufl., München.

Rahmeyer, F. (2005): Wirtschaftliche Entwicklung oder evolutorischer Wandel: Ein integrativer Versuch zur Fundierung der evolutorischen Ökonomik, Augsburg, Göttingen.

Raisch, S./Hargrave, T. J./van de Ven, A. H. (2018): The Learning Spiral: A Process Perspective on Paradox, in: Journal of Management Studies, 55. Jg., Nr. 8, S. 1507-1526.

Richter, R./Furubotn, E. G. (2003): Neue Institutionenökonomik: Eine Einführung und kritische Würdigung, 3. Aufl., Tübingen.

Schelsky, H. (1970): Zur soziologischen Theorie der Institution, in: Schelsky, H. (Hrsg.): Zur Theorie der Institution, Düsseldorf, S. 9-26.

Schirmer, F. (2013): Das duale Prozessmodell dynamischer Fähigkeiten: (Mikro-)Politische Desiderata und Rekonstruktionsperspektiven, in: Zeitschrift für Personalforschung, 27. Jg., Nr. 1, S. 525.

Schirmer, F. (2016): Innovationsfähigkeit, Institutionelle Reflexivität und Politik in Organisationen: Politische Interpretationen des Konzepts „Institutionelle Reflexivität“, in: Moldaschl, M./ Manger, D. (Hrsg.): Im Spiegel der Organisation: Innovationsfähigkeit durch institutionelle Reflexivität, München, Mering, S. 39-61.

Schirmer, F./Knödler, D./Tasto, M. (2012): Innovationsfähigkeit durch Reflexivität: Neue Perspektiven auf Praktiken des Change Management, Wiesbaden.

Schreiber, D. (2015): Narrative der Globalisierung, Wiesbaden.

Schreyögg, G./Kliesch-Eberl, M. (2007): How dynamic can organizational capabilities be? Towards a dual-process model of capability dynamization, in: Strategic Management Journal, 28. Jg., Nr. 9, S. 913-933.

Schumpeter, J. (1997): Theorie der wirtschaftlichen Entwicklung: Eine Untersuchung über Unternehmergewinn, Kapital, Kredit, Zins und den Konjunkturzyklus, 9. Aufl., Berlin.

Scott, W. R. (2001): Institutions and Organizations, 2. Aufl., London.

Senge, P. M. (2001): Die fünfte Disziplin: Kunst und Praxis der lernenden Organisation, 8. Aufl., Stuttgart.

Sydow, J./Schreyögg, G./Koch, J. (2009): Organizational Path Dependence: Opening the Black Box, in: Academy of Management Review, 34. Jg., Nr. 4, S. 689-709.

Thornton, P. H./Ocasio, W. (2008): Institutional Logics, in: Greenwood, R./Oliver, C./Suddaby, R./ Sahlin-Andersson, K. (Hrsg.): The SAGE handbook of Organizational Institutionalism, Los Angeles, London, New Delhi, Singapore, S. 99-129.

Viehöver, W. (2014): Erzählungen im Feld der Politik, Politik durch Erzählungen: Überlegungen zur Rolle der Narrationen in den politischen Wissenschaften, in: Gadinger, F./Jarzebski, S./ Yildiz, T. (Hrsg.): Politische Narrative, Wiesbaden, S. 67-91. 
Vrontis, D./Thrassou, A./Santoro, G./Papa, A. (2017): Ambidexterity, external knowledge and performance in knowledge-intensive firms, in: Journal of Technology Transfer, 42. Jg., Nr. 2, S. 374388.

Weick, K. E. (1995): Sensemaking in Organizations, Thousand Oaks.

Weick, K. E./Westley, F. (1999): Organizational Learning: Affirming an Oxymoron, in: Clegg, S. R./ Hardy, C./ Nord, W. R. (Hrsg.): Managing Organizations: Current Issues, London, S. 190-208.

Wolf, W. (2002): Das Problem der Narrativität in Literatur, bildender Kunst und Musik: Ein Beitrag zu einer intermedialen Erzähltheorie, in: Nünning, V. (Hrsg.): Erzähltheorie transgenerisch, intermedial, interdisziplinär, Trier, S. 23-104.

Womack, J. P./Jones, D. T. (2003): Lean thinking: Banish waste and create wealth in your corporation, 1. Aufl., New York.

Wrona, T. (2005): Die Fallstudienanalyse als wissenschaftliche Forschungsmethode, Berlin.

Yin, R. K. (2003): Case study research: Design and methods, 3. Aufl., Thousand Oaks.

Norman Meisinger ist wissenschaftlicher Mitarbeiter am Lehrstuhl für Sozioökonomik an der Zeppelin Universität Friedrichshafen.

Anschrift: Zeppelin Universität Friedrichshafen, Lehrstuhl für Sozioökonomik, Fallenbrunnen 3, D-88045 Friedrichshafen, Tel.: +49 (0)7541 600925 27,

E-Mail: n.meisinger@zeppelin-university.net

Der Verfasser dankt den anonymen Gutachtern für die wertvollen und tiefschürfenden Anmerkungen. 